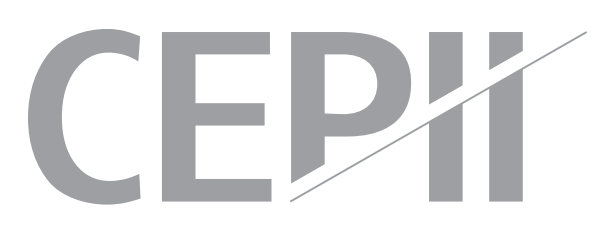

\title{
Immigration and Worker-Firm Matching ${ }^{\star}$
}

\author{
Gianluca Orefice ${ }^{\dagger} \&$ Giovanni Peri†
}

\section{Highlights}

- In labor markets characterised by large dispersion of workers' productivity and worker-firm complementarity, high quality firms have strong incentives to screen for the quality of workers. This implies positive assortative matching and an increase in the average productivity.

- Immigration, by increasing the variance of workers abilities, may drive stronger PAM between firms and workers.

- Using French matched employer-employee (DADS) data over the period 1995-2005 we document that positive supply-driven changes of immigrant workers in a district increased the strength of positive assortative Matching and the average productivity of the district.

- One percentage point increase in the supply-driven share of immigrants in the district implies an increase in the share of positive assortative matches (net of mismatch) by 3.3 percentage points. This corresponds to a $30 \%$ reduction in the PAM gap between a district belonging to the $25^{\text {th }}$ percentile of the PAM intensity distribution and the Parisian labor market.

\footnotetext{
* This work beneted from a State aid managed by the National Agency for Research, through the program "Investissements devenir" with the following reference: ANR-10-EQPX-17 (Remote Access to data CASD).We are grateful to Frederic Docquier, Lionel Fontagné, Hillel Rapoport, Ariell Reshef, Gonzague Vannoorenberghe and participants to seminars held at University of Paris 1, Cergy-Pontoise, IESEG, Paris School of Economics, Université Catholique de Louvain and OECD-CEPII Migration conference for insightful comments.

† University of Paris-Dauphine, CEPII and CESifo - gianluca.orece@dauphine.psl.eu

†† University of California, Davis and NBER - gperi@ucdavis.edu
} 


\section{Abstract}

The process of matching between firms and workers is an important mechanism in determining the distribution of wages. In a labor market characterised by large dispersion of workers' productivity and worker-firm complementarity, high quality firms have strong incentives to screen for the quality of workers. This process will increase the positive quality association of firm-worker matches known as positive assortative matching (PAM). Immigration in a local labor market, by increasing the variance of workers abilities, may drive stronger PAM between firms and workers. Using French matched employer-employee (DADS) data over the period 1995-2005 we document that positive supplydriven changes of immigrant workers in a district increased the strength of PAM. We then show that this association is consistent with causality, is quantitatively significant, and is associated with higher average productivity and firm profits, but also with higher wage dispersion. We also show that the increased degree of positive assortative matching is mainly reached by high-productive firms "losing" lower quality workers and "attracting" higher quality workers.

\section{Keywords}

Matching, Workers, Firms, Immigration, Productivity.

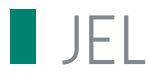

F16, J20, J61.

\section{Working Paper}

\section{CEPI}

CEPII (Centre d'Etudes Prospectives et d'Informations Internationales) is a French institute dedicated to producing independent, policyoriented economic research helpful to understand the international economic environment and challenges in the areas of trade policy, competitiveness, macroeconomics, international finance and growth.

CEPII Working Paper
Contributing to research in international
economics
@ CEPII, PARIS, 2020
All rights reserved. Opinions expressed
in this publication are those of the
author(s) alone.

Editorial Director: Sébastien Jean

Production: Laure Boivin

Published on March 31, 2020

No ISSN: $1293-2574$
CEPII

20, avenue de Ségur TSA 10726 75334 Paris Cedex 07 +33153685500 www.cepii.fr Press contact: presse@cepii.fr 


\section{Immigration and Worker-Firm Matching ${ }^{1}$}

Gianluca Orefice (University of Paris-Dauphine, CEPII and CESifo)*

Giovanni Peri (University of California, Davis and NBER) ${ }^{\dagger}$

\section{Introduction}

Recent studies have shown that a significant part of wage differences across similar workers is due to their location and the employer they work for. Geographic location, and especially the density of economic activity around one's workplace, have been associated with large wage premia (e.g. Glaeser and Mare 2001; Combes, Duranton and Gobillon 2008; and De La Roca and Puga 2017). More recently the quality of the firm where a worker is employed, and the specific worker-firm match, have also been shown to explain a significant percentage of workers' wage differentials (Abowd, Kramarz and Margolis 1999; Bernard, Jensen, Redding and Schott 2007; Card, Heining and Kline 2013). Those components of a worker's wage may also be related to each other as the location of a worker affects the employment options available locally and the type of worker-firm matching taking place (Dauth et al. 2018).

In particular, local conditions can affect the wage of individuals independently from his/her characteristics by attracting better "quality" firms or by affecting the efficiency of worker-firm matches. Part of the "location premium" in wages, associated with places where productivity and wages are high, is driven by the fact that "good" locations are good because they attract good firms and may facilitate Positive Assortative Matching (PAM hereafter), namely the matching of high-quality workers with high-productivity firms. This last feature, in the

\footnotetext{
${ }^{1}$ This work benefited from a State aid managed by the National Agency for Research, through the program "Investissements devenir" with the following reference: ANR-10-EQPX-17 (Remote Access to data CASD). We are grateful to Frederic Docquier, Lionel Fontagné, Hillel Rapoport, Ariell Reshef, Gonzague Vannoorenberghe and participants to seminars held at University of Paris 1, Cergy-Pontoise, IESEG, Paris School of Economics, Université Catholique de Louvain and OECD-CEPII Migration conference for insightful comments.

*gianluca.orefice@dauphine.psl.eu

†gperi@ucdavis.edu
} 
presence of complementarities between workers and firms' quality would generate average wage and productivity gains as well as higher dispersion of wages in "good" locations.

Dauth et al. (2018) analyzes whether local density is associated with better average quality of firms and with the intensity of PAM between firms and workers in that location. They find that high economic density encourages stronger PAM. The reason that economic density may increase PAM is that in thicker labor markets firms may have better access to information on workers, due to repeated interactions and frequent contact, and top quality firms may be more aggressive in screening and attracting high quality workers, generating a strong PAM. In the presence of complementarity between firm and worker quality, the aggregate result of PAM is higher average surplus created, higher average wages and firms' profits, and higher dispersion of wages in local labor markets.

In this paper we analyze whether an inflow of foreign workers increases the extent of PAM between firms and workers in a region. Immigration increases the size of the local market, and through a simple "scale" effect, it may enhance the positive "thickness" externalities analyzed in Dauth et al. (2018). However, beyond yielding a simple increase in density, immigration of foreign-born is also likely to increase the variety of local abilities. Immigrants come from different backgrounds, cultures and experiences, and the range and variety of their abilities are likely to be more dispersed than for natives. Moreover, due to linguistic and cultural barriers their specific quality may be harder for local employers to assess, especially in early interactions. In this paper we develop the hypothesis that when the share of immigrants in a labor market becomes larger, this drives higher variance in the unobserved quality of workers, and higher uncertainty from the employers' point of view on the actual type of workers. As a consequence, in the presence of productive complementarity in the quality of firms and workers, high quality firms have stronger incentives to conduct screening of workers because their return to a "positive match" is larger. Thus high-quality firms hire and retain high-quality workers (as they can pay higher wages) leaving low-quality workers to low-quality firms. Hence the degree of positive assortative matching increases in areas with more immigrants. This has positive effects on average productivity and average wages in the 
labor market. However, it also generates larger dispersion of wages. ${ }^{2}$

To test this hypothesis we use matched employer-employee data in all French districts in the years 1995-2005. With these data we calculate the average quality of workers and firms over the whole period, and can observe their match each year as in Card et al. (2013); Davidson et al. (2012); and Dauth et al. (2018). We then approximate the strength of PAM in two ways: first, using the rank correlation between worker and firm quality in a district (Dauth et al. 2018); second, using the (net) share of positive assortative matches in the district, calculated as share of firm-worker matches where both parties are above or both below the mean quality net of the share of mismatches (mismatches are calculated as those matches where firms are above median quality and workers below, or vice-versa), as in Davidson et al. 2012. We then analyze whether the change in immigrant share in each district is associated with the change in these measures. Put more simply, we analyze whether the presence of immigrants increases the strength of the positive quality association of firmworker match: do high-quality firms become more likely to employ high-quality workers in labor markets with more immigrants? To address the endogeneity problem of immigration, we propose a modified approach of the shift share instrument à la Card (2001). We use the past share of immigrants across districts, interacted with predicted (rather than observed) inflows of immigrants based on the origin-specific flows of immigrants to other EU-15 countries (excluding France). ${ }^{3}$ To test the validity of this modified shift-share instrument, we check its correlation with pre-period economic and demographic variables as suggested by GoldsmithPinkham et al. (2019), and subject it to a plausible exogeneity test following Conley et al. (2012). The use of this instrument and its validity checks are not novel contributions of the paper, but they ensure that our use of the IV strategy is sound. The innovation we offer is the analysis of assortative firm-worker matching as a local channel through which increased immigration in a region may affect firm outcomes and, through their matches with workers,

\footnotetext{
${ }^{2}$ This effect is different from other potential productivity effects analyzed in the literature, even when considering search and matching. In Chassamboulli \& Palivos (2014) and Battisti et al. (2018), for example, immigration attenuates the effects of search frictions in the labor market, decreasing the equilibrium unemployment, but the impact works through a job creation channel different from that of this paper.

${ }^{3}$ By using the predicted inflows of immigrants we purge the IV of any France-specific factor that may have attracted immigrants from a specific place-of-origin. We draw on the idea of Autor et al. (2013) who instrument the Chinese import penetration of US districts by using the non-US exposure to Chinese imports.
} 
average productivity and wages.

We show evidence that an increase in the share of migrant workers in a district is associated with stronger assortative matching between firms and workers. This result is robust to the specific measure of assortative matching and to different proxies for firm and worker quality. ${ }^{4}$ The IV estimates show results consistent with a causal effect of larger immigrant share on stronger assortative matching. In particular, a one percentage point increase in the supply-driven share of immigrants in the district implies an increase in the share of positive assortative matches (net of mismatch) by 3.3 percentage points; corresponding to a $30 \%$ reduction in the PAM gap between a district belonging to the $25^{\text {th }}$ percentile of the PAM intensity distribution and the Parisian labor market (which belongs to the top $75^{\text {th }}$ percentile of the distribution). We also document that this effect is particularly strong in districts with a higher dispersion of immigrant worker types (i.e. where the dispersion of unobserved worker quality is higher and firms have stronger incentives to screen).

We then provide some insight into the re-allocation of workers through which assortative matching is achieved. As we cannot observe directly the screening intensity of firms, we analyze the types of moves across firms to check if they are consistent with our view that assortative matching is achieved via screening. In particular, better screening would be highly valuable to high-quality firms as immigration increases, so one should observe the strongest transition of high-quality workers toward high-quality firms. Similarly, the high-quality firms should be those getting rid of low-quality workers at higher rate. In line with this prediction, in response to immigration, we see that high-quality workers (those above the median of the quality distribution) become much more likely to transition from low- to high-"quality" firms (those respectively below/above the median of the firm quality distribution). Similarly, low-quality workers (below the median of the worker quality distribution) become more likely to make the the opposite transition from the top two quartiles of firm quality toward the bottom. This movement of workers in response to immigration is consistent with higher screening from the top quality firms, and explains the mechanism underlying the positive

\footnotetext{
${ }^{4}$ In section 3.2 we describe how we approximate the quality of workers and firms, while in section 4 we describe the two measures of PAM adopted in the paper.
} 
effect of immigration on the strength of PAM.

The main contribution of this paper is the identification and quantification of an additional channel through which immigrants have an effect on the average productivity, wage, and on wage distribution in receiving economies. The effect of immigration on worker-firm matching highlighted in this paper provides an additional unexplored mechanism that may contribute to explain the positive productivity effect of migration shown empirically in the previous literature (Peri 2012; Mitaritonna, Orefice and Peri 2017). This channel may also contribute to explain the non-negative effect of immigrants on native average wages in local labor markets (Card 2005, Dustmann et al. 2013, Ottaviano \& Peri 2012, Pischke \& Velling 1997).

Two research branches in the literature are related to this paper. The first is the growing literature on what affects matching across firms and workers in local labor markets. Davidson et al. (2012) show that trade liberalization improves the degree of matching for exportoriented industries. In the same vein, Davidson et al. (2014) shows that export-oriented sectors display a higher correlation between firm and worker types. Using French firm level data, Bombardini et al. (2019) show that the workforce composition of exporting firms has lower dispersion of worker types than domestic firms; this supports the idea that exporters have higher incentive to screen for high quality workers. Dauth et al. (2018) find that high local density encourages stronger PAM. In thicker labor markets, high quality firms may be more effective in attracting high quality workers, generating strong positive assortative matching. The second branch of the literature to which this paper contributes is that on the local economic consequences of migration. The new channel highlighted in this paper provides an additional explanation for the non-negative effect of migration on the average wages of native workers highlighted in the literature (see Friedberg and Hunt 1995 and Lewis and Peri 2015 for surveys of the labor market effect of migration). ${ }^{5}$ While the findings of small wage effects and possible positive productivity effects from immigration are common in

\footnotetext{
${ }^{5}$ Other explanations for the small effect of migration on native wages include the productivity increases resulting from more efficient allocation of tasks between native and migrant workers, migrant and native workers' complementarity, and a boost in innovation at the aggregate level (Peri 2012; Peri and Sparber 2009) and at firm level (Mitaritonna et al. 2017).
} 
the literature, ${ }^{6}$ to the best of our knowledge this is the first paper that focuses on assortative matching between firms and workers across local labor markets as a channel to explain the non-negative wage effect of immigration. The only (partial) exception is a recent theoretical contribution by Burzynski \& Gola (2019) that includes a matching mechanism-not empirically tested - in a general equilibrium model with heterogeneous firms and migration. We develop a much simpler model to illustrate how higher dispersion in worker ability, due to higher shares of immigrants, can generate stronger local assortative matching in the presence of screening. While we do not directly observe screening by firms, we test some implications of the model relative to the degree of assortative matching, immigrant inflows, and the transition of high-/low-quality workers toward high-/low-quality firms.

The remainder of this paper is organized as follows. In section 2 we present the theoretical framework intended as a guide for the empirical exercise. In sections 3 and 4 we respectively discuss the data, the measures used to approximate firm and worker quality, and the strength of PAM. In section 5 we discuss the empirical strategy and some stylized facts. In sections 6 we present the estimated effect of increased immigration on measures of assortative matching and on average district wages and profits and wage dispersion. In section 7 we analyze the impact of immigration on mobility and reallocation of workers across firms which represents the mechanism through which local labor markets increase their degree of assortative matching. The final section concludes.

\section{A simple model}

In our empirical analysis we consider whether an increase in the share of immigrants within a labor market increases the intensity of positive assortative matching. This means that higher-quality firms match with higher-quality workers, and lower-quality firms with lowerquality workers. If firms have imperfect knowledge about workers' quality and if the presence of immigrants increases the variance of workers' quality (types) then, in the presence of

\footnotetext{
${ }^{6}$ Card (2005) found that immigrants had little if any effect on wages at the local labor market level. Similarly Pischke \& Velling (1997) and Dustmann et al. (2013), respectively for Germany and UK, do not find any negative effect of immigration on the wages of native workers.
} 
strong complementarity between quality of firms and quality of workers, the more productive firms have larger incentives to screen when there are more immigrants in the market. More firms doing screening will result in a higher probability of PAM. This is due to the fact that high-quality firms have a larger return to matching with higher-quality workers, and hence their premium from assortative matching increases as the quality of the top workers increases. Stronger assortative matching will also generate higher average productivity and higher average profits among firms within each local labor market, as well as a higher dispersion of productivity. ${ }^{7}$ In this section we propose a simple model to illustrate such mechanism in the context of local labor markets with native and migrant workers who differ only in the different dispersion of their quality distribution. We first show the key results for an economy with only two quality (types) of workers and firms: high- and low-productivity. We then generalize the main insight and result to the case of $N$ types (quality levels) for workers and firms.

\subsection{Model with two types of Firms and Workers}

Consider an economy with labor force of unit mass, in which the average quality/effectiveness of labor, equal to $\theta_{w}$, is assumed to be larger than one. Workers in this labor market come in two different quality levels (types) with productivity equal to $\theta_{w}-\epsilon$, for the low productivity ones, and $\theta_{w}+\epsilon$, for the high productivity group. Both values are also assumed to be larger than one for simplicity. We assume that both groups have the same size so that each quality level of worker, denoted as $\mu=\left[\theta_{w}-\epsilon, \theta_{w}+\epsilon\right]$, comprises $1 / 2$ of the total labor force. We also assume that while all workers can observe their quality (type), firms cannot observe the specific quality of the worker. Therefore $\epsilon$ is also the standard deviation of the expected quality of workers in a group, from the firm's perspective. There is also a unit mass of firms with average quality (productivity) $\theta_{f}$ and among them half have relatively high quality $\theta_{f}+x$ and half of them have relatively low quality $\theta_{f}-x$ where both values are larger than one. This generates a distribution of firms over the quality levels $\phi=\left[\theta_{f}-x, \theta_{f}+x\right]$, with half of the firms in each group.

\footnotetext{
${ }^{7} \mathrm{~A}$ similar mechanism is analyzed for the effect of trade liberalization on the intensity of assortative matching by Helpman et al. (2010) and Davidson et al. (2008).
} 
Each firm $j$ matches to one worker $i,{ }^{8}$ and produces surplus (value added) according to the following production function, in which the quality of firms and workers are complementary:

$$
Y_{i, j}=\left(\mu_{i} * \phi_{j}\right)
$$

This expression is a special case that captures the complementarity between the quality of firm and workers and the super-modularity of production. ${ }^{9}$ Once the match has taken place and production begins, the surplus is split equally between wage of the worker and profit of the firm, so that the wage of worker $i$ is: ${ }^{10}$

$$
W_{i}=\frac{\left(\mu_{i} * \phi_{j}\right)}{2}
$$

and the profit of firm $j$ is:

$$
\Pi_{i}=\frac{\left(\mu_{i} * \phi_{j}\right)}{2}
$$

We assume that the firms have imperfect information and cannot distinguish the identity of high- and low-quality workers without screening them. Those with quality $\theta_{w}+\epsilon$ and $\theta_{w}-\epsilon$ will look identical to each firm. Firms, however, can pay a cost of screening, $K$, after which they are able to perfectly observe worker quality. For the moment we assume that this screening cost is equal for each firm (in the next section we relax this assumption).

The incentives to pay the cost of screening are higher for the high-quality firms in each group as they have a larger profit to earn from matching with high-quality workers, due to the convexity of production and complementarity between high-quality firms and highquality workers. Hence if the screening cost is below a certain threshold the high-quality firms (those with quality $\theta_{f}+x$ ) will pay the screening cost and will match with high-quality

\footnotetext{
${ }^{8}$ In a recent paper Eeckhout \& Kircher (2018) show that assortative matching happens across firms of different size (i.e. when the firm matches with many workers). In their model the firms choose both the quality and the quantity (size) of their workforce. In this case, positive assortative matching not only depends on the degree of complementarity between types, but also on the complementarity between types and quantity.

${ }^{9}$ The logic is that high-quality workers are paid more not only because of their innate quality, but also because they work for high quality firms (as in Kremer 1993).

${ }^{10}$ The surplus can be split in any proportion between firm and worker. We choose $1 / 2$ for simplicity.
} 
workers, leaving low-quality workers to low-quality firms. This is, in effect, positive assortative matching. However, if the screening cost, to be paid ex-ante, ${ }^{11}$ is above a certain threshold, high quality firms will not pay it and there will be random matching in terms of quality of the workers, assuming that firm and workers meet at random. The expected profit of the high-quality firms when screening and matching with the best quality workers is:

$$
E\left(\pi_{S}\right)=\frac{\left(\theta_{w}+\epsilon\right)\left(\theta_{f}+x\right)}{2}-K
$$

Their expected value when they do not screen and match randomly with workers is:

$$
E\left(\pi_{R}\right)=\frac{0.5\left(\theta_{w}+\epsilon\right)\left(\theta_{f}+x\right)+0.5\left(\theta_{w}-\epsilon\right)\left(\theta_{f}+x\right)}{2}
$$

Therefore high quality firms will screen if $E\left(\pi_{S}\right)>E\left(\pi_{R}\right)$ which implies:

$$
K<\frac{1}{2} \epsilon\left(\theta_{f}+x\right)
$$

If this condition is satisfied then the high-quality firms will screen and they will match with all the high-quality workers, leaving the unmatched low-quality workers to the low-quality firms. Hence, if the condition above is satisfied, full assortative matching prevails in this model, meaning that high-quality firms will match with high-quality workers only, and low-quality firms with low-quality workers only. Notice that in this model what matters is the screening cost for the high-quality firms. Those are the firms that, conditional on having paid the screening cost $K$ and thus having observed worker quality, will choose to match with all the high-quality workers (notice that every high-quality worker would be employed by highquality firms as they pay higher wages). Hence, what matters is whether high-productivity firms decide to screen or to match randomly. If the cost of screening $K$ is different between high- and low-productivity firms, then it is the screening cost of high-productivity firms that

\footnotetext{
${ }^{11}$ The screening cost can be thought also as a period of trial in which the high-quality firm learns the type of workers and then starts production only if the worker is high-quality.
} 
determines whether these firms screen of match randomly. Once high-productivity firms screen and hire all high-quality workers and pay them more, the low-quality firms will match with the remaining low-quality workers.

Two simple implications derive from the equation above:

1. If the cost of screening is equal across firms in a labor market, then the probability of observing high-quality firms screening for high-quality workers in that market is monotonic in the threshold value of $K$, and increases with the standard deviation of workers' quality $\epsilon$

2. For common screening costs, the probability of screening will be higher for firms in areas with higher average productivity, $\theta_{f}$.

\subsection{The role of immigrants}

We now introduce the population of immigrants to the model. Immigrants are treated as having a larger standard deviation of types (uncertainty) but the same average quality of native workers. Immigrants come from different backgrounds, so their adjustment to local labor markets can be very different. In general their background and the quality of their education and working experience can be very different. Overall, as they come from different countries, they are a more heterogeneous group than natives in their quality, even controlling for their observable characteristics. We can think of this as a result of their country of origin diversity, but also as a result of the different selection that they have in different countries (positive from some countries and negative from others, as predicted by Borjas 1987). We will test the assumption of higher quality dispersion of immigrants in the data in several ways - see section 4.1.2. In our simple model, this feature is captured by the following condition: $\epsilon_{I}>\epsilon_{N}$ where "I" indicates immigrants and " $N$ " native workers. This immediately implies that in a population of all immigrants, the probability of screening by the high-quality firms is higher than in a population of all natives and therefore assortative matching would be more likely for a given screening cost.

When the population in a labor market is a mixture of the two groups ( $I$ and $N)$, so is 
the average value of workers' $\epsilon$ which would be equal to $\left[\epsilon_{l} * s h_{l}+\epsilon_{N} *\left(1-s h_{l}\right)\right]$, where $s h_{l}$ is the share of immigrants in the total population of workers. Then the condition for high-quality firms to perform screening is:

$$
K<\frac{1}{2}\left[\epsilon_{l} * s h_{l}+\epsilon_{N} *\left(1-s h_{l}\right)\right]\left(\theta_{f}+x\right)
$$

In this case the probability of screening and assortative matching increases in the share of immigrant workers $s h_{l}$ as long as the standard deviation of immigrants' quality is larger than that of natives' quality (and as long as their average quality is the same). This will be a key implication that we test in the empirical part of the paper, namely:

Proposition 1 For a given cost of screening, local markets with a larger share of immigrants have a stronger incentive to perform screening which will result in PAM between workers and firms.

A corollary of (Proposition 1 ), based on equation 7 , is that the probability of PAM is larger when the dispersion of immigrant quality, $\epsilon_{l}$, is larger. We test this additional implication too:

Corollary 2 The effect of immigrant share on the incentive to perform screening and on improved PAM between workers and firms is magnified in local labor markets with a greater dispersion in immigrant quality.

Another important implication of the model above is that average value-added (surplus) and profits of firms will be larger in markets where PAM occurs, and hence will be positively associated with the share of immigrants. This is easily proven by writing the difference between average surplus with PAM and average surplus with random matching for firms. This difference is:

$$
E\left(S_{S}\right)-E\left(S_{R}\right)=\frac{1}{2}\left[\left(\theta_{w}-\epsilon\right)\left(\theta_{f}-x\right)+\left(\theta_{w}+\epsilon\right)\left(\theta_{f}+x\right)-\left(\theta_{w}-\epsilon\right)\left(\theta_{f}+x\right)-\left(\theta_{w}+\epsilon\right)\left(\theta_{f}-x\right)\right]
$$


The expression easily simplifies into $(2 \epsilon X)$, which is always larger than 0 as long as $\epsilon$ and $x$ are greater than 0 . Hence the average surplus in a region with PAM is always larger than the average surplus in a region with random matching. This difference, equal to $(2 \epsilon X)$, grows in the standard deviation of workers' quality and the standard deviation of firms' quality. As workers and firms split the surplus (see equations 2 and 3), the inequality in the expected surplus in equation (8) will carry over also to firms' average profit no matter how the surplus is split. So the final implication of our simple model is that:

Proposition 3 Local markets with larger shares of immigrants (i.e. wider dispersion in unknown types) have higher average firm profits.

This proposition will also be tested in the empirical section of the paper. Additionally, PAM will increase the standard deviation of workers' wages and of firms' profits as the match distribution will be concentrated on the extreme outcomes, $\left(\theta_{f}-x\right)\left(\theta_{w}-\epsilon\right)$ and $\left(\theta_{f}+\right.$ $x)\left(\theta_{w}+\epsilon\right)$, rather than on the intermediate ones, $\left(\theta_{f}+x\right)\left(\theta_{w}-\epsilon\right)$ and $\left(\theta_{f}-x\right)\left(\theta_{w}+\epsilon\right)$. Hence:

Proposition 4 A higher share of immigrants (i.e. wider dispersion in unknown types) will be associated with higher wage- and profit-dispersion.

Notice that as the screening cost is paid ex-ante, once firms conduct any screening in a market they will screen all workers, and they will therefore also generate positive assortative matching for native workers. Hence if the cost of screening is such that firms would not screen when all workers are natives but they will screen when there is a sufficiently large share of immigrants, then the presence of immigrants will also increase the assortative matching of natives and therefore their average wages in the region. This positive impact on the matching of natives takes place only if there is initial uncertainty about the quality of natives. If firms can perfectly observe the quality of natives without screening, then the "spillovers" from screening on better matching native workers does not occur. The fact that there also exists a non-negligible share of mismatches between workers and firms in districts with lower immigration shares (as shown in table 2) suggests the presence of imperfect information on 
the quality of native workers.

\subsection{Model with many types of firms and workers and different screening costs}

Let us now consider an economy similar to the one described in the previous section, but with $2 N$ types of firms and workers characterized by different productivity levels. In particular, workers' productivity can be any of the following $2 N$ levels $\left[\theta_{w}-\epsilon, \theta_{w}-\frac{N-1}{N} \epsilon, \ldots \theta_{w}-\frac{\epsilon}{N}, \theta_{w}+\right.$ $\left.\frac{\epsilon}{N} \ldots \theta_{w}+\frac{N-1}{N} \epsilon, \theta_{w}+\epsilon\right]$ so that one can rank their quality in increasing order from $i=-N$ to $i=N$ and $\epsilon$ is still a measure of overall quality dispersion. Similarly, assume that there are $2 N$ groups of firms of productivity equal to $\left[\theta_{f}-x, \theta_{f}-\frac{N-1}{N} x, \ldots \theta_{f}-\frac{x}{N}, \theta_{f}+\frac{x}{N} \ldots \theta_{f}+\right.$ $\left.\frac{N-1}{N} x, \theta_{f}+x\right]$. Let's also assume that each group of firms, indexed by quality index $j=$ $-N,-N+1, \ldots-1,+1, N-1, N$ pays a screening cost $K_{j}$. In this case, the firms of top level quality $(j=N)$, with productivity equal to $\theta_{f}+x$ are those with the strongest incentives to screen. These firms will screen if the generated surplus from paying the screening cost and assortatively matching with workers of top quality $\left(\theta_{w}+\epsilon\right)$ is larger than the surplus than matching randomly and not paying the screening cost. Namely:

$$
\left(\theta_{f}+x\right)\left(\theta_{w}+\epsilon\right)-K_{N} \geq \frac{1}{2 N}\left(\theta_{f}+x\right) \sum_{j=-N}^{+N}\left(\theta_{w}+\frac{\epsilon}{N} j\right)
$$

This inequality is satisfied if:

$$
K_{N} \leq\left[\epsilon-\frac{1}{2 N-1} \sum_{j=-N}^{N-1}\left(\frac{\epsilon}{N} j\right)\right]\left(\theta_{f}+x\right)
$$

The expression in square brackets in the inequality (10) above is linear and increasing in $\epsilon$, in $x$, and in $\theta_{f}$. Therefore, for a given screening cost, the higher is $\epsilon$ (the dispersion of workers' quality types), the higher is $x$ (which captures the dispersion of firm productivity), and the higher is average firm productivity $\theta_{f}$, the more likely the top-quality group of firms will be to screen. If the inequality is satisfied, the top firm types do the screening, match with the top quality workers, and the other $2 N-1$ firm types are left to decide whether to screen or 
to randomly match with the remaining $2 N-1$ workers types. In general, for a firm of quality type $M$ with costs of screening $K_{M}$, screening will be optimal if:

$$
K_{M} \leq\left[\frac{M}{N} \epsilon-\frac{1}{N+M-1} \sum_{j=-N}^{M-1}\left(\frac{\epsilon}{N} j\right)\right]\left(\theta_{f}+x\right)
$$

The expression in square brackets in the inequality (11) above is linear and increasing in M. Therefore as we move to lower quality firms the incentive to do screening decreases monotonically. This has the following two implications that generalize the results from a two-type model to this multi-type model:

1. For a cost of screening that is constant among firm types or declining with quality, $M$, there will be a "marginal quality group" such that all groups of higher quality pay the screening cost and match assortatively, and those with lower quality do not screen and match randomly. This is an immediate consequence of the fact that the threshold for screening in (11) is increasing in $M$. For screening costs that are excessively high, no firm will screen; for very low screening costs, all firms will screen.

2. For a given level of screening costs, the share of firms doing screening (and therefore the intensity of assortative matching) increases in the dispersion of quality types of workers. The share of firms doing assortative matching will always be positively selected in terms of quality.

The key insight of the multi-type model, confirming the two-type model, is that an increased dispersion in quality of workers leads to an increased share of firms doing assortative matching, and this in turn increases average profits and average wages. This is an interesting and new channel, to the best of our knowledge, through which higher shares of immigrants may have a positive effect on the average matching and average wages of natives in a region. We will test this channel in the empirical section.

While this model is extremely simplified, the basic intuition that a larger dispersion of worker quality makes screening more profitable for high-quality firms and increases the share of 
positive assortative matches (and therefore the average wages and productivity when firm and worker quality are complementary) is a very robust implication of our model. It holds for 2 and for $\mathrm{N}$ quality groups, and as $\mathrm{N}$ becomes larger this can approximate a continuum of quality levels.

\section{Data and measures of worker and firm quality}

Our empirical analysis consists of three steps which we develop in Sections 4, 5 and 6. First, we compute proxies capturing workers and firms' quality/productivity. In doing so, we assume that individual quality (of workers and firms), being an innate characteristic, remains constant over the period of analysis (1995-2005) and we estimate it using different methods. First, we apply the method pioneered by Abowd et al. (1999) and perfected by Card et al. (2013) to separate in a wage equation the individual and firm components, and we use those as measures of firm's and a worker's quality, respectively. Aware that these measures can be imprecise and, particularly for firms, may not be highly correlated with actual productivity (Eeckhout \& Kircher 2011), we also follow Bartolucci et al. (2018) in using more direct measures of productivity and profitability of firms as measures of the quality of firms. In the second step, we calculate two measures of the strength of positive assortative matching between firms and workers in each of the 101 French Districts, separately, for each year between 1995 and 2005. ${ }^{12}$ Following, respectively, Dauth et al. (2018) and Davidson et al. (2012), we calculate two proxies for the positive correlation between firm and worker quality across employer-employee matches for each district and year. Finally, we analyze in a reduced form regression at the district-year level whether the presence of immigrants is correlated with the intensity of positive matching between workers and firms in French districts. A French district is an administrative unit, smaller than regions, which is the combination of few labor markets. It is the only geographic level of aggregation for which data on immigration can be collected in a consistent way over our sample period, and between the data sources used to build our instrumental variable. This is the reason for conducting our analysis at

\footnotetext{
${ }^{12}$ Because of data availability in 1982 (used to build the IV) in our empirical exercise we use only 92 districts (we mainly get rid of overseas districts).
} 
the district level. While this choice may reduce the variation of the explanatory variable, measurement error is kept to a minimum by using these units. ${ }^{13}$ By using an instrumental variable approach, we also try to establish a causal link between immigration and the intensity of assortative matching. Before describing the aforementioned empirical steps, we provide a detailed description of the dataset employed in this paper.

\subsection{Data}

Our empirical analysis uses two main data sources: (i) matched employer-employee French data (Déclaration Annuelle des Donnée Sociales - DADS), and (ii) balance sheet data for the universe of French firms (FICUS/FARE).

DADS is an administrative database collected by the French Statistics Office (INSEE) and containing information on the employment structure of the universe of French firms. All wage-paying firms and legal entities located in France are obliged to report information to DADS on their workforce composition. For each worker we have information on annualized real earnings, total number of hours worked, gender, year, and place of birth (France vs foreign-born), occupation (4-digit PCS-ESE classification), experience, district of residence, and the industry of the employer. ${ }^{14}$ Two versions of the DADS data are used here. DADS Postes includes the entire workforce in France and has been used to compute the total employment of native and immigrant workers across French districts. Unfortunately, DADS Postes does not provide information on the worker's ID, so information on a single worker cannot be linked over time in a longitudinal panel to estimate the "individual fixed effect" over the worker's career (i.e. the wage decomposition as in Abowd et al. 1999 and Card et al. 2013). To construct the two measures of worker type adopted in this paper, based on lifetime wage and worker's wage decomposition (as defined in the next section), we need to follow each individual across years. Hence we use DADS Panel. This represents a (one in twelve) subsample of individuals born in October of each year, for which the DADS Panel

\footnotetext{
${ }^{13}$ The use of smaller geographic areas, such as French zone d'emploi, would imply an imprecise allocation of immigrants over time and therefore generate significant measurement error in the explanatory variable of interest.

${ }^{14}$ We do not have information on the country of origin of foreign-born workers nor on their education levels.
} 
provides a worker identifier (nninouv) that enables us to follow individuals over time.

We construct our sample to maximize the precision of the data on wages and the information on employers. This turns out to be the sample of full-time workers in the manufacturing sector. To do this, we focus on full-time jobs (more comparable in terms of wage) held by workers in the manufacturing sector (for which we have detailed balance sheet information on the employer from FICUS/FARE data) in each year from 1995 to 2005 . The limitation of the sample to the manufacturing sector, implies that we only use spells of workers while they work in this sector to estimate our wage equation. Some workers can move in and out of the manufacturing sector, but only the working spells within the manufacturing are used to estimate the worker specific effect. Moreover, we only consider job spells with one employer at a point in time. Focusing on full-time jobs helps to reduce the dispersion in hours worked which could add noise to the measure of workers' quality that should be based on differences in marginal productivity (i.e. hourly wages) rather than in hours worked (see Card et al. 2013). In Table 1 we provide the number of full-time workers, for every year, who can be tracked over time thanks to their ID and do not have missing information on annual wages. On average, more than one hundred thousands workers per year can be tracked over time and therefore considered in our calculations of worker quality types (i.e. worker's wage decomposition and lifetime wage as discussed in the next section). $4.5 \%$ of workers move every year (from firm to firm), identified as workers with an employer identifier (SIREN) within the manufacturing sample changing between time $t-1$ and $t$ (see the fourth column of Table 1 for the number of workers that change firm by year, i.e. movers). ${ }^{15}$ In DADS data (panel and postes) each firm is identified by a unique identification code (called SIREN), so DADS data can be easily merged with balance sheet data, available only for manufacturing firms, which we use to compute characteristics of the firm, including measures of its productivity.

- Table 1 about here -

The firm identifier SIREN is assigned by the French statistical office (INSEE) for administra-

\footnotetext{
${ }^{15}$ This is a crucial statistic in the AKM decomposition (see next section). Worker quality (productivity), in fact, can be identified only if there are enough workers moving across firms and connecting them such that we can separate out a worker from a firm effect.
} 
tive purposes and may potentially combine multiple plants in France. Most firms only have one plant, and the great majority of multi-plant firms have plants in the same district, so that the location of the firm (headquarters) and of the plant(s) coincide in the overwhelming majority of cases. Only $2 \%$ of firms in our sample have plants (workers) in more than one district. Hence the location of one firm in one district ensures that our local analysis is accurate. ${ }^{16}$ Notice that the firm identifier changes when a firm changes its ownership. This means that when a SIREN disappears from the dataset, it does not necessarily signify the "death" of the firm (similarly, the entry of a new SIREN does not necessarily signify the "birth" of a new firm). We consider a change in ownership as a potential change in the firm type (as done also in Card et al. 2013), and estimate separate employer quality for the firm before and after the change in ownership, as the two instances of the firm can be distinct along several dimensions. A new owner may introduce new managerial practices and/or technologies that change the quality of the firm (and thus the firm-type).

FICUS/FARE data report standard balance sheet information (value added, sales, total employment, capital, intermediate inputs, industry etc.) for the universe of French manufacturing firms over the period 1995-2005. These data are used to compute the Value Added Per Worker (here used as the main proxy for the quality of firms) and the Total Factor Productivity of firms over time (here used as an alternative proxy for the type of firms in appendix). For coherence with the DADS data, we drop firms that employ part-time workers only. We also exclude from the sample all firms with a missing SIREN code. Finally, our estimation sample includes on average more than 32,000 firms with a median size of approximately two hundred employees (see Table 1). FICUS/FARE data are also used to compute district specific control variables such as the average capital-labor ratio and the intermediate input intensity of firms in the district - see section 6.1. The district's export intensity, used as an additional control variable in section 6.1 , has been computed by aggregating firms' exports from French Customs at the district level.

\footnotetext{
${ }^{16}$ In section 6.1 we propose a robustness check excluding large firms who are likely to have plants in different districts.
} 


\subsection{Quality of workers and quality of firms}

In order to identify and estimate firm-specific and worker-specific quality, we first follow the wage decomposition proposed by Abowd et al. (1999) - AKM hereafter - as well as Card et al. (2013) and Dauth et al. (2018), among others. In particular, we estimate a Mincerian wage regression over the whole 1995-2005 period. We regress the $(\log )$ individual yearly wage of full-time manufacturing workers on worker fixed effects $\left(\alpha_{i}\right)$, firm fixed effects $\left(\Phi_{\mathbf{J}(i, t)}\right){ }^{17}$ and a set of observable individual characteristics $\left(X_{i, t}\right)$ including year dummies, a quartic polynomial in experience, an /le de France dummy, ${ }^{18}$ a gender dummy, and gender interacted respectively with experience, Ile de France, and year dummies. The estimated equation is as follows:

$$
\ln (\text { wage })_{i, t}=\alpha_{i}+\Phi_{\mathrm{J}(i, t)}+X_{i, t}+r_{i, t}
$$

In this specification, the worker fixed effect $\left(\alpha_{i}\right)$ can be interpreted as the time invariant component of worker's productivity which is rewarded equally across employers. It can therefore be used as a proxy for the quality of a worker. The assumption is that such quality does not vary over the period considered, because it is intrinsic to worker's characteristics and skills and it is uncorrelated with the firm specific component $\left(\Phi_{\mathbf{J}(i, t)}\right)$. Similarly $\left(\Phi_{\mathbf{J}(i, t)}\right)$ can be interpreted as a firm-specific component of the wage, invariant over time. More specifically, the firm fixed effect $\left(\Phi_{\mathrm{J}(i, t)}\right)$ obtained using the AKM method is a proportional wage premium paid by a specific firm $j$ to all employees (this is the firm's component of surplus-sharing in a standard log-additive wage setting model). ${ }^{19}$ In a robustness check we slightly depart from the original AKM decomposition, and add the broad occupation category of workers among the set of controls $X_{i, t}$ with the aim of capturing the observable, formal skills of workers. ${ }^{20}$

\footnotetext{
${ }^{17}$ The function $J(i, t)$ gives the identity of the unique firm $j$ employing worker $i$ at time $t$.

${ }^{18}$ Following Abowd et al. (1999) we include an Ile de France dummy to control for the specificity of the Parisian labor market.

${ }^{19}$ As in Card et al. (2013), we use the iterative conjugate algorithm to estimate individual and firm fixed effects. ${ }^{20}$ Occupation categories are: (i) skilled white collar, (ii) unskilled white collar, (iii) skilled blue collar, and (iv)
} 
The identification of worker-specific effects and firm-specific effects relies on workers moving across firms over the period considered, and on the assumption that any other wage component which is specific to the firm-worker match is not systematically correlated with either the firm or the worker quality. In our sample, as reported in Table 1, 4.5\% of workers move across different firms annually, so that over the 10 year period more than half of workers have worked for at least two employers in our sample. ${ }^{21}$ This implies a significant degree of mobility over the considered period. This reduces but does not eliminate the concern of limited mobility bias in our sample. In appendix 2 we discuss and check the orthogonality conditions underlying the AKM decomposition and the estimation results. In particular, we show the symmetry in wage gains for individuals moving from firms in the top to firms in the bottom quartile of productivity, relative to those moving from bottom to top. This is lends confidence to the notion that movers do not select a specific firm based on the expected wage component of the worker-firm match (i.e. movers do not sort across firms based on the match component of the expected wage). In appendix 2 we also show that a fully saturated model with job-specific fixed effects yields only a slight improvement in the fit of the data relative to the model we estimate (including only firm and individual effects), as suggested by the very small increase in the R-squared from 0.947 to 0.95 when saturating with employer-employee fixed effects. This is also evidence that match-specific effects are not very relevant for explaining productivity (wage) in an employer-employee match, implying that the individual and firm components in a linear combination explain most of the variance in log wages. Finally, in Table B1 we show descriptive statistics of the parameters obtained from the estimation of equation (12). Notice that the AKM parameters obtained using French data are similar to those obtained by Dauth et al. (2018) and Card et al. (2013) on German data. Namely, we obtain the same mean (and median) worker and firm effects as in Dauth et al. (2018). Also, we obtain a correlation between worker and firm fixed effects which is small and in line with Dauth et al. (2018) when they use the 1985-1991 period. In line with both Dauth et al. (2018) and Card et al. (2013) we obtain that the standard

unskilled blue collar.

${ }^{21}$ Assuming that one worker moves only once over the sample period. 
deviation of worker effects is larger than that of firm effects.

We also consider alternative measures of worker and firm quality-which rely on stronger assumptions but are easier to calculate. For workers, we consider the average residual lifetime wage; for firms, the value added per worker. The worker's average residual lifetime wage, conditional on observable characteristics, is generated as follows. We first regress individual (log) wage on experience, sector, and year dummies. We then take the residual of this regression, and average it across the years over which the individual is observed in the data. This measure captures the average lifetime wage, controlling for observables, which is a proxy of the average productivity/quality of a worker. Controlling for sector and year fixed effects allows us to obtain a residual wage purged by year trends and industry heterogeneity in wage setting. Since in the period 1995-2005 we observe workers at different stages of their careers, so we also purge the residual wage of the effect of the worker's experience. The advantage of this measure is that it is intuitive, easy to calculate, and a robust statistic. The disadvantage is that it includes location and firm-specific effects, which may be correlated with individual quality.

None of the worker-quality proxies described above is perfect; they each have strengths and weaknesses. For this reason, in what follows we adopt both measures to calculate the strength of assortative matching and test the effect of migration on PAM. It will be important to show that our results are robust to the specific measure of worker's type adopted.

As far as a firm's quality measure is concerned, the firm fixed effects from the AKM decomposition, while often-used, may be a rather poor measure of firm quality with respect to productivity. Firm fixed effects represent the employer-specific component in wage setting (see Abowd et al. 1999; and Card et al. 2013), ${ }^{22}$ but it is a coarse measure of productivity/quality of firms. It is not always true that firms with higher productivity level pay higher wages. A recent strand of literature suggests that when wages are non-monotonic in firm type, then firm fixed effects in AKM decomposition do not necessarily reflect the firm pro-

\footnotetext{
${ }^{22}$ Many papers analyzing the role of the workplace component in rising wage inequality have used firm fixed effects from AKM decomposition as a measure of the surplus obtained by all employees in a given firm (i.e. employer-share of the surplus in a wage setting environment). See Abowd et al. (1999); and Card et al. (2013).
} 
ductivity type (de Melo 2018, Eeckhout \& Kircher 2011, Gautier \& Teulings 2006). Hence, in the same vein as Bartolucci et al. (2018), we adopt an alternative measure of firm quality which more closely captures productivity compared to the wage-pay potential: the labor productivity of a firm in a given year measured as Value Added per Worker, VAPW. ${ }^{23}$ From our empirical analysis we can also (indirectly) argue whether worker-firm matching increases the total potential payroll paid to workers (as revealed by AKM firm fixed effects), or the total value-added generated by them. In the first case it is the firm-specific wage matters, while in the second it is the productivity of the firm that matters, assuming in both cases that wage captures the worker's productivity.

We choose the productivity measure of the firm as the main proxy for the type of firm. However, in a robustness check in Table A3 we provide baseline results using firm fixed effects from the AKM decomposition as a proxy for the type of the firm. As a further robustness check, in appendix Table A4 we follow de Melo (2018) and use the average coworker type as a proxy for firm type. In the de Melo (2018) approach, the strength of positive assortative matching is approximated by the correlation between worker type and the average type of his/her coworkers. Finally, in Table A4 we also report a robustness check using TFP (rather than value added per worker) as a proxy for the type of firm.

\section{Measuring within district assortative matching}

Following Davidson et al. (2012), a first measure of the intensity of assortative matching between workers and firms in each French district is represented by the difference between the share of positive assortative matching and the share of mismatches in each district. The share of positive assortative matching in the district is the sum of the share of high-quality workers employed in highly-productive firms, $\pi_{H H}$, and the share of low-quality workers employed in low-productivity firms $\left(\pi_{L L}\right)$, where high (low) quality workers/firms are those above (below) the median of worker/firm distribution (in each district). By contrast, the share of mismatch involves the share of high-quality workers in low-productivity firms $\left(\pi_{H L}\right)$, and the share of

\footnotetext{
${ }^{23}$ In the appendix section we use the Total Factor Productivity (TFP) of firms as an alternative proxy for firm-type. TFP of firms has been calculated using the Wooldridge (2009) approach.
} 
low-quality workers in highly-productive firms, $\left(\pi_{L H}\right)$. The strength of matching in a given district $d$ at time $t$ is equal to $\left(\pi_{H H}+\pi_{L L}\right)-\left(\pi_{H L}+\pi_{L H}\right)$. In line with Dauth et al. (2018), the second proxy we use for the strength of matching in the district is the rank correlation between worker and firm type within a district in a given year (setting to zero statistically non-significant correlations, where the the p-value of the rank correlation is below 0.10 ). Based on their type, we rank workers and firms within each district and compute the rank correlation between firm- and worker-types for each local labor market and year. In the next sections we show important descriptive evidence on the assortative intensity of worker-firm matching, in relation to average productivity and the presence of immigrants across French districts.

\subsection{Stylized facts on within-district matching}

Before moving to the formal econometric estimation, we provide descriptive evidence characterizing: (i) the match between firms and workers in France (fact 1 - see section 4.1.1), (ii) the empirical distribution of migrant workers' quality relative to natives' quality (fact 2 - see section 4.1.2), (iii) the correlation between the average productivity of districts and the strength of assortative matching between firms and workers in the district (fact 3 - see section 4.1.3), and (iv) how the presence of migrants in each district correlates with the strength of assortative matching (section 4.1.4). These facts together establish the presence of assortative matching and its positive correlation with immigrants and productivity. These facts are in line with the implications of our simple model and support some of the assumptions made.

\subsubsection{Fact 1: Worker-Firm match (and mismatch) across French districts}

Figures 1 and 2 plot the empirical distribution of workers types (approximated respectively by lifetime wage and by worker fixed effects from the AKM decomposition) for individuals employed by high- and low- productivity firms as measured by Value Added per Worker. The two figures show that highly productive firms-defined as those having Value Added per Worker above the $75^{\text {th }}$ percentile of the distribution (solid line)-employ (on average) 
higher quality workers relative to low-productivity firms-defined as those with value added per worker below the 25th percentile (dashed line in figures 1 and 2). While this correlation in the overall sample also shows a large share of worker-firm "mismatches", the figure reveals a degree of positive assortative matching, albeit imperfect. ${ }^{24}$

- Figure 1 and 2 about here -

As further evidence of the matching across French districts, in Table 2 we report the share of positive assortative matching $\left(\pi_{H H}, \pi_{L L}\right)$ and mismatch $\left(\pi_{L H}, \pi_{H L}\right)$, in 1995 and 2005 for: (i) all French districts (top panel of the table); (ii) high-immigration districts, which are those with an immigrant-share above the median (central panel); and (iii) low-immigration districts (bottom panel). We use Value Added per Worker as proxy for the firm type, and lifetime conditional wage as a proxy for worker type. The table clearly shows that the share of positive assortative matching (around 60\% in most cases) is larger than the share of mismatched firms (about 40\%). The presence of a significant amount of mismatch, however, is consistent with the idea that there are significant information asymmetries or searching costs in the labor market (even in districts with small shares of immigrants-bottom of Table 2). ${ }^{25}$ The numbers shown in Table 2 are similar to those obtained by Davidson et al. (2012) on Swedish data. About $60 \%$ of the firm-worker matches are assortative, and about $40 \%$ are mismatched, which implies non-random but also imperfectly assortative matching.

- Table 2 about here -

\subsubsection{Fact 2: Worker-quality distribution and immigrant-intensity}

An important condition, assumed in the model, is that immigrants have a more disperse distribution of individual qualities with respect to natives. This implies that firms face higher degrees of uncertainty in immigrants intensive labor markets, and this would make a match

\footnotetext{
${ }^{24}$ If we define firm productivity according to the firm-effect in AKM, the overall firm-worker quality correlation is actually very small and negative.

${ }^{25}$ In a world without screening cost or with perfect information, the worker-firm match would be perfectly assortative, hence there would be an absence of mismatch.
} 
with the "right" worker more valuable, while avoiding a match with the "wrong" worker also becomes more important. This section shows that the empirical distribution of migrant workers' quality is actually more dispersed than that for native workers. First, in Table 3 we show that the average quality of native workers - as captured by average lifetime wage-is slightly larger than that for migrants, but quite close to it. More importantly, both the standard deviation and the interquartile range of worker types are 10-20\% larger for immigrants than for native workers. This is true when we use residual lifetime wage and it is even stronger when we use AKM worker fixed effects as a proxy for worker quality.

\section{- Table 3 about here -}

An additional preliminary way to show the association between the presence of immigrants and the uncertainty/dispersion in worker quality is to check their correlation across districts. To do so, in Table 4 we regress six moments of the worker type distribution in each district, i.e. $5^{\text {th }}, 10^{\text {th }}, 25^{\text {th }}, 75^{\text {th }}, 90^{\text {th }}$ and $95^{\text {th }}$ percentile, on the share of immigrants residing in the district. Controlling for region-by-year fixed effects and district-specific control variables (including the average worker type in the district), Table 4 shows negative coefficients for percentiles of the wage distribution below the median, and positive coefficients for percentiles above the median. This supports the idea that the presence of immigrants across districts is associated with a more dispersed distribution of worker quality across French districts. Their presence is associated with lower quality low-percentile types and higher quality of high percentile types. This is consistent with the idea that a greater immigrant-presence widens the distribution of worker quality in a district, because of the larger dispersion of immigrants' quality.

In Table A1 in the appendix, we replicate the same type of estimation using different measures of workers' quality dispersion, such as the standard deviation, the interquartile range, and the max-min difference in worker types for each district. Conditional on region-by-year fixed effects and district-specific controls, districts with high shares of immigrants show a larger dispersion of worker quality as suggested by a positive coefficient for the standard deviation, 
and the interquartile and min-max ranges. ${ }^{26}$

- Table 4 and A1 about here -

\subsubsection{Fact 3: Positive matching, districts' productivity and employment}

If stronger assortative matching leads to an improvement in the allocation of labor within French districts, then it should be associated with a higher level of average labor productivity. This is shown in Table 5 where we report the correlation between the strength of assortative matching and the average value added per worker in the district. Controlling for district and region-by-year fixed effects, we find that the degree of assortative matching (as revealed by the rank correlation between firm and worker type) is significantly positively correlated with the average productivity of the district. Similarly, the strength of matching - the share of positive assortative matching minus the share of mismatch-is positively correlated with the productivity of the district. Table 5 also shows that the association is similar whether we use AKM fixed effects or average residual wage as the measure of worker quality. ${ }^{27}$

- Table 5 about here -

\subsubsection{Immigration and positive matching: a first glance at data}

Figure 3 provides a sense of the correlation between migration and positive assortative matching across French districts. In the vertical axis we plot the 10-year change, between 1995 and 2005 , in the degree of assortative matching as revealed by worker-firm quality rank correlation (panel $a$ and b) and strength of positive assortative matching (panel $c$ and d). As a proxy for worker type we alternatively use lifetime conditional wage (panel a and c) and AKM worker fixed effects (panel $b$ and $d$ ). As a proxy for firm quality we use value

\footnotetext{
${ }^{26}$ Regressions reported in Table 4 and Appendix Table A1 include district-specific controls (population, share of skilled workers, and concentration index of firms in the district) to be consistent with the econometric estimations reported in section 5 .

${ }^{27}$ To check that our data match the findings obtained in previous literature we also show, in Appendix Figure A1, that the correlation between total population and positive assortative matching across districts is positive and significant. Dauth et al. (2018), show such correlation in German regions, and they suggest that denser districts have stronger positive worker-firm type correlations as a consequence of stronger assortative matching in denser and thicker labor markets.
} 
added per worker in all cases. On the horizontal axis we report the change in the share of immigrants for each district over the period 1995-2005. By taking long-run difference approach, district specific (time invariant) factors are controlled for. So the slope of the linear correlation reported in each panel of figure 3 is purged by district specific unobserved factors and within district change generates the correlation. All the scatter plots reported in figure 3 show a positive (albeit weak) correlation between the share of immigrants in the district and the strength of positive assortative matching. Districts where immigrants increased their presence in the population also experienced an increase in the degree of positive assortative matching between firms and workers. While the correlations are not extremely strong (these may be affected by the presence of omitted variables), this is in line with Proposition 1 in section 2 .

\section{Immigration and firm-worker matching at the district level}

This section discusses the empirical strategy we adopt to test the effect of exogenous migration shocks on the strength of positive assortative matching across French districts. In section 5.1 we present our baseline econometric specification, while in section 5.2 we discuss the identification strategy and the Instrumental Variable approach aimed at solving the potential endogeneity and omitted-variable problems.

\subsection{Empirical Model}

In order to get closer to testing whether inflows of immigrants causally affect the quality correlation of worker-firm matching across French districts, we employ the following empirical specification:

$$
y_{d, t}=\beta_{1} I m m i S h_{d, t}+\beta_{2} X_{d, t}+\theta_{d}+\theta_{r t}+\epsilon_{d, t}
$$

where the subscript $d$ and $t$ stand respectively for district and year; $\theta_{d}$ and $\theta_{r t}$ are district 
and region-by-year fixed effects (there are 23 regions in France and each of them includes on average 4 districts). ${ }^{28}$ District fixed effects control for any district-specific (time invariant) factor that may affect the firm-worker match in the local labor market. In particular, district fixed effects control for the average productivity of firms in the local labor market $d$, which has a role in affecting the probability of assortative matching in our theoretical framework (see eq. 6 in section 2.1). Region-by-year fixed effects are then included to control for any region-specific time trend driven by specific regional policies or economic shocks that may have an effect on the hiring process and on firm dynamics, such as changes of labor laws or local competition conditions. The set of control variables $X_{d, t}$ includes: (i) the concentration index of firms in the district, i.e. the Herfindahl-Hirschmann index of firms' market share in a specific district; ${ }^{29}$ (ii) the (log) population of native workers in the district; (iii) the share of skilled over total workers in the district. The concentration index captures possible market power of local firms that may affect matching behavior in local labor markets. The (log of) native workers in the district aims to control for the size/density of the district and of the local labor market. Using German data, Dauth et al. (2018) show that in big cities and/or in more dense local labor markets the strength of assortative matching may be stronger. Finally, we control for the share of skilled workers in the district because skill biased technical change can increase the degree of positive assortative matching (see Acemoglu 1999 and Albrecht and Vroman 2002), and the intensity of such change is associated with the presence of skilled workers.

The main explanatory variable is the share of immigrants in the total workers' population in each district-year. In order to test Proposition 1, the dependent variable $y_{d, t}$ is alternatively: (i) the rank correlation between firm and worker type; and (ii) the strength of positive assortative matching defined as $\left(\pi_{H H}+\pi_{L L}\right)-\left(\pi_{H L}+\pi_{L H}\right)$, where $\pi_{i j}$ is the share of workers of type $i$ employed in a firm with productivity type $j .{ }^{30}$ This is the measure used in Davidson

\footnotetext{
${ }^{28}$ We follow the official classification of French regions in force over the period 1995-2005. Because of data availability for the IV we use 92 districts.

${ }^{29}$ The Herfindahl-Hirschmann for firm concentration has been calculated as $H H_{d, t}=\sum_{i=1}^{l} s_{i t}^{2}$, where $s_{i t}$ is the market share of firm $i$ in its district $d$ at time $t$.

${ }^{30}$ As discussed in section 4, high (low) types of workers/firms are those above (below) the median of the worker/firm distributions in each district.
} 
et al. (2012). We also use firm profit as a dependent variable in order to test Proposition 2.

Firm profits are calculated as total revenues minus total cost of the firm (wage bill, purchase of intermediate inputs and raw materials). ${ }^{31}$

\subsection{Identification and IV strategy}

Considering the empirical specification discussed in the previous section, as the change in immigrant share across districts over time is not random, we might be concerned that Ordinary Least Square estimates do not identify the causal effect of immigration on assortative matching (endogeneity). The inclusion of district and region-by-year fixed effects absorbs some of the unobserved variables, likely linked to economic and demographic conditions, that may affect both the share of immigrants and the hiring behavior of firms. Nevertheless, economically more successful districts may experience an inflow of immigrants in addition to a change in the hiring process of firms, leading to less-efficient worker-firm matching (when the economic performance of a district is favorable, the intensity of PAM may decrease because firms are less "picky" in choosing their ideal worker or because tighter labor markets imply difficulty for firms in finding the ideal worker). To address this issue we rely on an Instrumental Variable (IV) shift share approach (the so called "enclave" instrument) proposed by Card (2001) and refined in several subsequent studies. Aware of the criticism that this IV strategy has received, especially in the recent period (see Jaeger, Ruist and Sthuler 2018; Goldsmith-Pinkham, Sorkin and Swift 2019) ${ }^{32}$ we introduce some modifications aimed at reducing the potential correlation of initial immigrants shares with subsequent economic changes, and we subject the IV to some validity checks. ${ }^{33}$ The first modification

\footnotetext{
${ }^{31}$ We aggregate firms' profit at the level of district by a weighted average with weights equal to the size of the each firm (i.e. the share of firm's sales over total sales in the district).

${ }^{32}$ Specifically, Jaeger et al. (2018) argue that the standard shift-share instrument, being based on the past settlement of immigrants, is highly correlated over time and potentially correlated with pre-period and current economic conditions. This implies that the coefficient associated with a shift-share instrumented variable captures both the short and the long run (feedback) effect of migration, where the long-run effect may be correlated with persistent demand shocks. To avoid this problem, Jaeger et al. (2018) propose including in the regression the lagged instrumented migration shock to control for the feedback effect. In our empirical framework, the inclusion of district fixed effects implies that the long-run feedback from past migration and demand should be absorbed and only the short-term change in immigration identifies the impact.

${ }^{33}$ In section 5.2.3 and in the Appendix 3 we test further the validity of our IV by applying the tests proposed by Goldsmith-Pinkham et al. (2019).
} 
is to use the predicted number of immigrants to France from country $o$ in year $t$ based on the origin-specific flows of immigrants to other EU-15 countries (excluded France). ${ }^{34}$ Such an adjustment eliminates the potential correlation of France-specific economic factors that may generate inflows of immigrants from specific places-of origin, and also be especially correlated with the economic performance of some specific districts. By doing so, the shock component of the enclave approach is based on exogenous (non-France specific) push factors (as suggested by Goldsmith-Pinkham et al. 2019 for the validity of the enclave approach). ${ }^{35}$ The constructed variable approximates the supply-driven component of migration from each origin country by measuring migration toward countries other than France. Specifically, using OECD bilateral migration flows data, we regress the total inflows of migrants in France from each origin $O$ at time $t-I_{m m i} i_{F R, O, t}$ - on the inflow of migrants from $O$ to all other EU-15 countries $\left(/ m m i_{E \cup 15, o, t}\right)$, controlling for origin and year fixed effects:

$$
\operatorname{Immi}_{F R A, o, t}=\beta_{1} \operatorname{Immi}_{E \cup 15, o, t}+\theta_{o}+\theta_{t}+\epsilon_{o, t}
$$

The predicted values from regression (14), $\widehat{\operatorname{Immi}}_{F R A, O, t}$, net of the origin and year fixed effects, ${ }^{36}$ represent the origin-specific predicted inflows of immigrants in France, based on the variation of immigrant inflows in other (similar) countries. Following Card (2001), we therefore allocate the predicted inflows of immigrants from a given origin $O, \widehat{\operatorname{Immi}}_{F R A, O, t}$, using the spatial distribution of immigrants across French districts in 1982 (from Labor Force

\footnotetext{
${ }^{34}$ This approach is broadly inspired by the trade shift-share used in Autor et al. (2013). In that paper the import penetration of China in the US is approximated by the supply-driven component of Chinese exports, i.e. the exposure to Chinese imports of countries other than the US. See Autor et al. (2013) section B for more details.

${ }^{35}$ See Goldsmith-Pinkham et al. (2019) section 8.4.

${ }^{36}$ The predicted inflows of immigrants are $\widehat{I m m i}_{F R A, o, t}=\widehat{\beta}_{1} / m m i_{E U, o, t}$. From the fit of equation 14 we eliminate the year fixed effects component because it may capture French specific shocks, common across districts, and affecting the localization of immigrants. We also remove the origin fixed effects component to avoid time-invariant, origin-specific patterns of migration affecting our IV.
} 
Survey data, LFS): ${ }^{37}$

$$
\widehat{\mid M M I}_{d, t}=\sum_{o} \frac{\mid M M I_{d, o, 1982}}{\mid M M I_{F R A, o, 1982}} * \widehat{I m m i}_{F R A, o, t} .
$$

Notice that the spatial distribution of immigrants in 1982 pre-dates the creation of a common EU labor market (1992) and hence pre-dates by more than a decade the large flow of EU immigrants in France. Moreover the economic conditions are relative to more than a decade prior to the beginning of the considered period. This makes the initial distribution of immigrants likely to have very low correlation with recent economic trends in the district. Some validity checks on the initial distribution of immigrants by origin are discussed in section 5.2.3 and in Appendix section 3. Finally, we calculate the share of immigrants in each (district) as follows:

$$
\widehat{s_{d, t}^{\mid \widehat{M I I}}}=\frac{\mid \widehat{M M I}_{d, t}}{\mid \widehat{M M I}_{d, t}+\text { Natives }_{d, 1982}}
$$

In expression (16) the native population is fixed at year 1982 so as to avoid spurious effects due to the potentially endogenous native population growth in the district over the 19952005 period. ${ }^{38}$ For the validity of this variable as an IV, the size of the existing immigrant communities in 1982 must not be correlated with district-specific changes of labor and economic conditions between 1995 and 2005 (conditional on controls and fixed effects included in the equation 13). This is reasonable, as there is a lag of more than ten years between the initially-observed immigrant distribution and the beginning of our analysis. Moreover, the aggregate inflow of immigrants from each origin country must be independent of the labor demand of any specific French district. This is likely to hold, as we use the predicted inflow of immigrants from each origin country based on the supply-driven component of migration toward similar destination countries other than France (EU15).

\footnotetext{
${ }^{37}$ For coherence with LFS data-here needed to compute the spatial distribution of immigrants across districts in 1982 - the OECD IMD data have been aggregated by the same set of origins (or group of origins) used in the LFS data.

${ }^{38}$ Being based on (exogenous) inflows of foreign-born workers, our IV is purged by the inter-districts movement of French workers (internal migration of French workers).
} 
Nevertheless, to increase confidence in the validity of our instruments we test whether the short and long-run pre-1995 trends in labor market outcomes across districts are correlated with the post-1995 variation in our IV. Table 6 presents the coefficients obtained by regressing the short-run changes in employment and average wage over the period 1994-1995 (see columns 1-2) as well as their long-run trends, over two consecutive LFS census (19821990), on the change in our IV (i.e. on the predicted inflow of immigrants) for the period 1995-2005. None of these correlations is statistically significant. This means that districts that received large inflows of immigrants in 1995-2005 due to increased push-driven migrant inflows did not perform differently in the previous decade (or in the year right before the sample) compared to those that received few immigrants. This is consistent with the validity of our instrumental variable, as it shows that pre-1995 trends in labor market outcomes across French districts are uncorrelated with the predicted post-1995 intensity of immigrant flows.

\subsubsection{Standard Shift-share IV}

The modification introduced to the standard shift-share IV aims at improving the exogeneity of the instrumental variable to contemporaneous, destination-specific unobservable shocks that may affect the settlement of immigrants and the local labor market dynamics. However, in order to check the robustness of our results, we also adopt the standard shift-share IV and present the results in Table 9. That is, we use the observed rather than the predicted immigration flows to France from each origin to augment the initial distribution of immigrants across districts.

\subsubsection{Deviation from the exclusion restriction}

The validity tests discussed above provide qualitative evidence that the instrumental variable is not correlated with pre-1995 labour market trends across French districts. However, there may still exist other omitted variables leading to violations of the exclusion restriction. To address any remaining concern of endogeneity, we apply the "plausible exogeneity" test proposed by Conley et al. (2012). The test allows for possible deviations from exact validity 
of the exclusion restriction (i.e. non-zero correlation between the instrument and the error term in eq. 13) and checks whether the estimate of the coefficient of interest $\left(I m m i S h_{d, t}\right)$ is robust to a range of such possible deviations. We therefore relax the exclusion restriction of our IV and assume a correlation between the instrument and the error term in equation (13) in the range $\gamma \in[-2 \delta ; 2 \delta] .{ }^{39}$ A prior on how far such a correlation is from the exclusionrestriction validity (i.e. $\gamma=0$ ), can be approximated by regressing the four measures of assortative matching on the instrumental variable $\left(\widehat{\left.s_{d, t}^{\mid \widehat{M M I}}\right)}\right.$, the endogenous variable $(/ \mathrm{mmi}$ $\left.S h_{d, t}\right)$, and the other control variables included in equation 13. The estimated coefficients on $\widehat{s_{d, t}^{I M M I}}$ (i.e. $\gamma$ ) are reported in Table A6. Then we follow Conley et al. (2012) and estimate the "Local-To-Zero" approximation confidence intervals by assuming $\gamma$ is normally distributed with zero mean and a variance $\delta=\gamma / 2$. In Table A6 we report the $95 \%$ confidential intervals produced using the Conley et al. (2012) test for the plausible range of $\gamma$. None of the $95 \%$ confidence intervals for $\beta_{1}$ resulting from plausible exogeneity regressions contains zero. This implies that the positive and significant effect of immigrants on the four measures of assortative matching, as revealed by our main IV estimations, is strongly robust to plausible deviations from the exclusion restriction.

\subsubsection{Other Validity Tests}

As discussed in Goldsmith-Pinkham et al. (2019) a crucial assumption for the validity of the shift-share instrument is the exogeneity of the initial origin-specific migration shares, in particular those that have high Rotemberg weights in affecting the average 2SLS estimation. ${ }^{40}$ In line with our expectations, the top-5 origin communities that affect the 2SLS estimator are: Other Countries n.e.c. (including South America and Asian countries), Other African Countries, Ex-Yugoslavia, Portugal and Algeria. ${ }^{41}$ For this sub-sample of origins we tested the absence of correlation between the initial shares of immigrants and: (i) the economic performance of districts in 1982 (see Table C2); and (ii) the level of strength of PAM in

\footnotetext{
${ }^{39}$ See Conley et al. (2012) section 4.

${ }^{40}$ Rotemberg weights reveal how sensitive is the 2 SLS average estimator on $/ \mathrm{mmi}$ S $h$ to non-exogeneity in any of the origin-specific migrant shares. More details are reported in Appendix section 3.

${ }^{41}$ The aggregation of origins adopted here is that of the original LFS data used to build the IV.
} 
1995 (see Table C3). In line with Goldsmith-Pinkham et al. (2019), these tests support the exogeneity of the initial share of immigrants and the overall validity of our 2SLS estimations. See Appendix 3 for a detailed discussion on such validity tests.

\section{Main results on immigration and matching}

We start by showing in Table 7 the OLS estimations of equation (13) using value added per worker as a proxy for firm type. We find weak evidence of a positive effect of migration on the strength of assortative matching, but no significant coefficient on rank correlation. Only when residual lifetime wage is used as a proxy for worker type, the coefficient on the variable migrant shares is positive and statistically significant. See column 3 in Table 7 . In Table A2 we adopt a weighted OLS estimator (with weights equal to the number of firms in the district as a share of total French firms) and the immigrant share turns out to be statistically significant also when the strength of assortative matching is approximated by the rank correlation between firm and worker types (as revealed respectively by lifetime wage and value added per worker). See column (1) in table A2.

\section{- Table 7 about here -}

Least squares estimates, as in Table 7 , however, may hide spurious correlations driven by current economic booms which may attract foreign-born and also reduce screening and assortative matching, as in good economic times high-quality firms may be less "picky" in choosing workers. Table 8 shows our main empirical specification, where we use 2SLS estimator addressing potential endogeneity/omitted variable concerns. From these specifications emerges clear evidence of a positive effect of migration, instrumented by the shift-share IV, on the four measures of intensity and strength of assortative matching across French districts. A comparison between the OLS and 2SLS results highlights the negative bias present in the OLS estimations. Unobserved positive economic shocks (such as demand shock in the districts) may attract immigrants and make the screening of workers less urgent. The effect of migrant share is positive and significant when assortative matching is measured by the rank correlation between firm- and worker-type (see Table 8 columns 1 and 2). The effect 
of migration is also positive when the strength of positive assortative matching is measured by the share of positive matching net of mismatches in the local labor market (see Table 8 columns 3 and 4 ). In line with Proposition 2, migration also positively affects the average profits of firms in the district. Results reported in Table 8 also show a strong positive correlation between skill intensity (last row of the table) and firm concentration on the strength of positive assortative matching in the district. Highly concentrated districts (where few big firms dominate the local labor market and are likely to have an advantage in screening and matching with high-quality workers) show stronger positive assortative matching. Also, consistent with Acemoglu (1999) and Albrecht \& Vroman (2002), we find that French districts populated by skilled intensive firms (employing skilled workers) have a greater degree of assortative matching.

\section{- Table 8 about here -}

The results discussed above are robust to alternative instrumental variables. Table 9 reports results using the more standard shift-share instrument described in section 5.2.1. Independently of the methodology used to compute the total inflows of immigrants in France over the period 1995-2005 (i.e. predicted $\widehat{I M M I}_{d, t}$ vs. observed inflows in equation 15), an increase in the instrumented share of immigrants implies a higher rank correlation between worker and firm types in the district (columns 1-2), and stronger assortative matching (columns 3-4).

- Table 9 about here -

In our baseline regressions, firm quality is approximated by productivity related measures (value-added per worker). However, if we are interested specifically in the wage paid, the firmspecific component (from the AKM decomposition) represents a valuable alternate proxy for firm-type (see Card, Cardoso, Heining and Kline 2018). Moreover, when positive (negative) productivity shocks translate into workers' wage increases (decreases), the pay premium of firms (firm fixed effects from an AKM decomposition) are a proxy for productivity measures. Thus as a robustness check of our baseline results we use AKM firm fixed effects as a proxy 
for firm type. ${ }^{42}$ Results reported in appendix Table A3 show (less strong) evidence of the positive matching effect of migration when firm types are approximated by an AKM firmspecific component. This confirms the results using a different proxy for firm quality. It is also consistent with a small rent-sharing elasticity to productivity, so that the pay premium at the firm level (AKM firm fixed effects) is only weakly correlated with productivity measures of the firm.

In terms of magnitude, the baseline results reported in Table 8 imply that a one percentage point (p.p.) increase in the district's share of immigrants is associated with a 3.3 p.p. increase in the (net) share of positively assortatively matched workers in the district (see column 3 in Table 8). This corresponds to $30 \%$ of the PAM intensity gap between a district belonging to the lowest quartile of the distribution (i.e. $25^{\text {th }}$ percentile) and one in the top quartile, like the Parisian district (Île de France). ${ }^{43}$ In other words, for a district belonging to the median of the distribution in the (net) share of positive assortative matches, 3.3 p.p. corresponds to an increase in the strength of PAM that fills the gap in the Parisian labor market.

\subsection{Robustness checks}

In this section we provide several types of robustness checks, adding control variables, changing some features of the data, and modifying the selection of workers in the sample. Previous papers have identified a positive impact of international competition-measured as export intensity-on the correlation of worker-firm matching at the industry and firm level (see Davidson et al. 2012; Davidson et al. 2014; Bombardini et al. 2019). To check whether openness to trade, potentially correlated with openness to immigrants at the district level, is a spurious cause for the positive relation found in our analysis, we perform robustness checks including the export intensity of the district (the log of total district exports) as a further control in equation (13). ${ }^{44}$ Moreover, Acemoglu (1999) and Albrecht \& Vroman

\footnotetext{
${ }^{42}$ Since AKM firm fixed effects have very small variation over time, for this robustness check we also rely on a pure cross-sectional identification and include only region-year fixed effects, i.e. we omit district fixed effects. Results including both district and region-year fixed effects are also reported in Table A3.

${ }^{43}$ The $25^{\text {th }}$ percentile in the distribution of the (net) share of positively sorted matches is 0.133 ; the median is 0.179. The observed value for Île de France (in the top quartile) is a net share of 0.223 .

${ }^{44}$ French Customs data are used to compute the total exports of firms located in a given district.
} 
(2002) show that skill-biased technical change may increase the incentives for positive assortative matching in local labor markets by increasing the gap between high- and low-skilled workers' productivity. While we already control for skill intensity in the district, we also add as controls the average capital-equipment intensity ${ }^{45}$ and the average value of intermediate inputs relative to total product, ${ }^{46}$ presenting the results in Table 10 . These are likely proxies for the technological complexity (skill-bias) in a district. Results in Table 10 show that the coefficient on the immigrant share is robust to the inclusion of these additional control variables.

\section{- Table 10 about here -}

The inclusion of additional control variables improves the precision of the IV (see first stage statistics reported at the bottom of Table 10) and confirms the results obtained in Table 8, and the positive impact of immigrants on rank correlation of the quality of firm-worker matching and of migration on average profits (see column (5) in Table 10). ${ }^{47}$ Consistent with Proposition 1 and 2, an exogenous inflow of migrants causes an increase in assortative matching and in the average profit of firms in the district. We then perform robustness checks using alternative proxies for worker and firm types (such as coworkers' type and TFP based firm type proxies, and occupation-conditioned worker-type proxies). Those are reported in Appendix section 1 Table A4, and all point to similar (albeit sometimes imprecisely estimated) positive effects of migration on the assortative matching of firms and workers. ${ }^{48}$

\footnotetext{
${ }^{45}$ Based on FICUS/FARE data we compute the ratio between physical capital and total employment in each firm, and then take the average across firms within a district.

${ }^{46}$ As a proxy for the intermediate input intensity we use the share between intermediate input purchases and the total value of production of the firm.

${ }^{47}$ In particular, a one standard deviation increase in the share of immigrants (standard deviation 0.044) implies a $96 \%$ increase in average profits. At first glance, this may appear a very large effect, but it is worth noting that one standard deviation increase in the share of migrants is extremely rare in France (it would imply that a district belonging to the 25 percentile of the distribution in immigrant share moved to the 75 percentile).

${ }^{48}$ In Table A4 we use the average coworker type as a proxy for the firm type (as suggested by de Melo 2018) and our baseline results hold. We find positive and significant effects of migration on the strength of assortative matching when approximated by the rank correlation (column 2) and the net share of positive matches in the labor market (column 4 in Table A4). In Table A4 we also report estimation results using TFP as a proxy of firm type, rather than their value added per worker. Again, we find support for a positive effect of migrant share on the strength of assortative firm-worker matching (statistically significant only when the worker type is approximated by lifetime wage). Finally, in Table A4 we use worker type proxies (both lifetime wage and AKM fixed effects) purged by the macro-occupation of the worker. In the calculation of the lifetime wage and in the AKM decomposition we condition the wage on the macro-occupation of the worker (i.e. white-
} 
One source of concern can be that the difference between the 2SLS and the OLS estimates is large. This is a sign of significant bias in the OLS estimates, potentially driven by the fact that immigrants are attracted to districts when they are economically booming. Those are also periods during which the intensity of assortative matches may decrease due to tighter labor markets making it more difficult for a firm to find the "right" match for a job. However, the presence of (potentially) endogenous controls $\left(X_{d t}\right)$ and district-year omitted variables may also generate such a difference. We test that the results in $2 S L S$ are robust to omitting the controls $X_{d t}$ (potentially endogenous) and to adding a district-specific trend so as to identify the effects on a within-district deviation around trend. In both cases, our baseline 2SLS estimates are robust. ${ }^{49}$

One insight of our model is that, if there is ex-ante uncertainty about the quality of native workers and the firm has to pay the screening costs ex-ante, not knowing whether it will match with a native or an immigrant, then a larger share of immigrants (which will make screening profitable, on average) will imply that the firm also screens native workers. This will result in a higher probability of assortative matching between firms and native workers. When screening becomes profitable, firms will screen all workers and more high-quality firms will match with high-quality natives. In the top part of Table 11 we specifically test whether exogenous inflows of immigrants affect the assortative matching intensity between native workers and firms. We find a positive and statistically significant effect of immigration on the strength of firm-native worker matching when native worker types are approximated by either lifetime wage or AKM decomposition fixed effects. This emphasizes better matching as a possible channel of positive spillovers from immigrants to native workers, and it helps explain why many previous studies on local labor markets have not found a negative average wage effect of migration on native workers.

\section{- Table 11 about here -}

collar high skilled, blue-collar high skilled, white-collar unskilled, blue collar unskilled). Our baseline results again qualitatively hold, with a positive (but imprecisely estimated) coefficient on migration when we use the occupation conditioned AKM worker fixed effects as a proxy for worker type.

${ }^{49}$ Results available upon request. 
In the bottom part of Table 11 we conduct the same exercise but using only migrant workers to compute our proxies for strength of assortative matching. This is an important robustness check for two reasons. First, migrant workers are plausibly more mobile across firms than natives. Second, imperfect information about worker type is more likely to apply for migrant workers (French employers have more info on the education level and type of natives than of migrant workers). For these two reasons we expect a stronger assortative matching effect of migration on the sub-sample of migrant workers. This is confirmed by the results in Table 11 , where the point estimates on the immigrant share are larger in magnitude for migrants than for natives matching measures - and in some specifications they are as much as two or three times larger. The larger quality dispersion of immigrants makes it particularly profitable for high-quality firms to match with the "right" immigrant workers.

Finally, we cut our sample in order to reduce noise and error. Specifically, we trim from our sample the largest and smallest firms. The presence of very small and very large firms (outliers) may have a disproportionate effect in influencing the proxies of assortative matching adopted here. We replicate our baseline estimations after excluding firms of size (number of employees) below the 5th and above the 95th percentiles in the size distribution. These firms are excluded from the calculation of the worker-firm rank correlation and strength of assortative matching. Results reported in Table A5 show the robustness of our baseline results to such trimming. ${ }^{50}$

\subsection{Immigration and wage dispersion}

The model in section 2 also suggests that a higher share of immigrants should be associated with a higher wage dispersion in the local labor market (see Proposition 3). In particular, the PAM effect of screening, induced by migration, would re-allocate high-type (low-type) workers toward high-type (low-type) firms and hence generate an increase in the wage gap between high- and low-type workers in each district. This section tests such a channel.

\footnotetext{
${ }^{50}$ The presence of multi-district firms is a small concern in our case as only about $2 \%$ of French firms are multidistrict. However, trimming large firms also represents a robustness check for the presence of multi-districts firms in our sample (indeed, large firms are more likely to be multi-district).
} 
Table 12 reports regression results using the difference in the (log) average wage between high- and low-type workers - respectively, workers with quality above and below the medianin each district-year (with worker type approximated in turn by lifetime wage in columns 1 and 2 and AKM fixed-effect decomposition in columns 3 and 4). This measure of dispersion is similar to the 75-25 log wage percentile difference in a district. Results in columns (1)(4) suggest that an increase in the share of immigrants is associated with a significant increase in the wage inequality in the district. Specifications (1) and (3) include district fixed effects, region-year fixed effects, and basic district controls while the other columns add district exports, average capital intensity, and intermediate input intensity. These results are consistent with the wage inequality effect of immigration in the UK highlighted in Dustmann et al. (2013).

\section{- Table 12 about here -}

\subsection{Heterogeneous effect based on immigrant quality dispersion}

An interesting corollary of Proposition 1 is that the probability of positive assortative matching is larger when the standard deviation of immigrant quality, $\epsilon_{l}$ is larger (see Corollary 1.1). This can be tested with a non-parametric bin approach; i.e. by interacting the share of immigrants in the district with bins constructed from percentiles of immigrant-type dispersion across districts-binned model. We therefore extend the empirical equation (13) as follows:

$$
y_{d, t}=\sum_{k}\left(\beta_{k} \text { Immi Sh }_{d, t} * \text { Dispersion } \operatorname{Bin}_{d, t 0}^{k}\right)+\beta_{2} X_{d, t}+\theta_{d}+\theta_{r t}+\epsilon_{d, t}
$$

where variables and subscripts have the same meaning as in the previous sections, $k$ is the number of bins adopted to explore the heterogeneous effect of migration on the strength of assortative matching $y_{d, t}$, and Dispersion $\operatorname{Bin}_{d, t 0}^{k}$ identifies whether the specific district $d$ belongs to a specific bin $k$ in at $t 0$ (1995). Based on the distribution of immigrant types in 1995 in each French district, we define: (i) bins for districts having an inter-quartile range 
of immigrant types above/below the median; and (ii) bins based on min-max difference in immigrant types in the district. ${ }^{51}$ We instrument each interaction between $/ \mathrm{mmi} S \mathrm{Sh}$ and the dispersion bin with the interaction between the instrument $\widehat{S_{d, t}^{T M M I}}$ and the dispersion bin. Results are reported in Table 13. We find that immigrant share has a positive, significant and stronger effect on the intensity of assortative matching in districts with a dispersion of immigrant types above the median (in 1995), while the effect is smaller and often nonsignificant for those with dispersion below the median. Results are confirmed also by using dispersion bins based on min-max difference in immigrant types as measure of dispersion. See columns 2, 4, 6 and 8 in Table 13. ${ }^{52}$ While rather noisy (F-stat below 10) these results are consistent with the idea that larger dispersion of immigrant quality is associated with even larger incentives for firms to screen with more likely assortative matching outcomes as high quality firm can hire high-quality workers.

- Tables 13 about here -

\section{Workers' Transitions across Firms}

In the previous sections we showed evidence of a positive effect of migration on the intensity of worker-firm positive matching across French districts. In this section we analyze the reallocation of high- and low-type incumbent workers (i.e. individuals with conditional lifetime wage above/below the median) across firms of different types. As we have emphasized in the model, the increased probability of screening should affect the allocation of all workers, including natives, across firms. More specifically, our model predicts that high-quality firms are going to be those more likely to screen as they benefit the most from improving the quality of their matches. To this end, we test the effect of immigrant share on the following outcomes: the number of high-quality workers moving from low- to high- quality firms, and the number of low-quality workers moving from high- to low-quality firms. Both moves are

\footnotetext{
${ }^{51}$ Here we use inter-quartile range and the min-max difference proxies for the dispersion of immigrant types in each district. We take these proxies in the initial year (1995) to reduce endogeneity concerns.

${ }^{52}$ The point estimates in columns 4 and 8 actually show larger coefficients for districts with migrants type distribution below the median. However, these are rather imprecisely estimated (with respect to coefficients for districts with migrants type distribution above de median) with a F-stat suggesting weak IV problem.
} 
a consequence of high-quality firms becoming more selective with their matches, and so are consistent with the screening described in our theoretical framework. ${ }^{53}$

Table 14 shows the 2SLS estimates of the impact of increasing immigrant share on mobility of high- and low-quality workers across high- and low-quality firms. Entry (1) in the top row shows the effect on the number of high-type workers moving from low- to high-type firms (respectively firms with value-added below and above the median). These are high-quality workers enticed to high-quality firms. The impact of immigration on this flow is highly significant and positive. On the other hand, immigration does not simply affect mobility between firms because the number of high-quality workers attracted by low-quality firms, estimated in specification (2) of row 1 , is not affected by immigrants. This implies that lowquality firms do not increase their screening or are not able to attract high-quality workers. Similarly, the second row of the table shows that immigration induces high-quality firms to screen out low-quality workers, increasing the number of those that move to low-quality firms. The opposite move (from low- to high-quality) is not affected by immigrants.

The results in this table show that, consistent with increased screening in high-quality firms, migration is associated with a transition of low-quality workers from high- to low-quality firms and of high-quality workers from low- to high-quality firms (see column 1 of the table). In particular, a one standard deviation increase in the share of migrants in a district more than doubles the number of movers from low- to high-productive firms (120\%increase). ${ }^{54}$ This suggests that stronger assortative matching induced by immigration is channelled by better screening among high-quality firms that attract high-quality workers and shed low-quality workers. Column 2 of Table 14 shows the effect of migration on the number of transitions going in the "wrong" direction, namely high-quality workers attracted by low-quality firms and low-quality workers pushed to high-quality ones. As those coefficients are much smaller and non-significant, immigration has no effect on the these flows, that would reduce assortative matching and generate a distribution of workers to firm closer to random.

\footnotetext{
${ }^{53}$ In Table A7 we show the number of workers that move across firms of different type each year. Workers that experienced unemployment spells larger than two years cannot be considered as movers for economic reasons, and are not included in these statistics.

${ }^{54}$ The in-sample standard deviation of $/ \mathrm{mmi} S h$ is equal to 0.04 .
} 


\section{- Tables 14 about here -}

Overall the evidence on inter-firm mobility in response to immigration suggests that a larger share of immigrants generates mobility of workers between firms to increase the intensity of assortative matching. In particular, there is evidence that some high- (low-) quality workers, who were in low- (high-) quality firms relocate to high- (low-) quality firms. This is consistent with the idea that presence of immigrants, by increasing the variety of skills, makes it more valuable for high-quality firms to screen and for them to attract high-productivity workers, both among immigrants as well as among natives.

\section{Conclusions}

This paper uses employer-employee matched data for the universe of French manufacturing firms to identify a new effect of immigration on local economies. Namely, we investigate whether immigrants promote positive assortative matching between firms and workers. What the empirical evidence suggests is that, in local areas (districts) where the share of immigrants increases, there is an increased tendency of high-productivity firms to hire high-productivity workers (both natives and immigrants), leaving less-productive workers to less-productive firms. This implies an increased strength of positive assortative matching in local labor markets. Improved PAM is then associated with larger firm profits, larger average valueadded, and higher average wages paid in the district. For this reason, our paper provides a new and additional explanation for the lack of negative effects of migration on native average wages found in many studies of the previous literature.

Using measures of worker and firm quality based on the AKM decomposition and on other firm-level productivity indicators, we first establish that the variability in workers' quality is higher for immigrants than for natives, while their average quality is comparable. Then we find that, in districts where the share of immigrants grew by one percent of the population, the rank-correlation between firm- and worker quality increased by 2 percentage points (when the worker type is approximated by residual lifetime wage), and the share of net positive assortative matches increased by 3.3 percentage points. This is a significant effect, as it 
represents a $5.5 \%$ increase in the average share of positive assortative matches (net of mismatches) across French local labor markets. We also find a positive effect on average firm profits and on wage dispersion.

We propose a simple model of asymmetric information and screening costs to rationalize why the inflow of immigrants would increase the percentage of firms involved in assortative matching. Namely, when the skill dispersion of workers becomes larger it is in the interest of the high-quality firms to do screening and select the best workers, leaving the lowerquality workers to lower-quality firms. Consistent with these predictions, we observe that districts in which migrant-share increases - and hence the dispersion of skills increases - highquality firms "lose" low-quality workers and "gain" high-quality ones, which is consistent with increased screening on their part.

This simple and novel mechanism introduces a new channel through which immigrants affect the local average wage and productivity for native workers. While the mechanism implies larger average wages and higher firm profit, it also implies higher wage dispersion and hence a potentially negative effect on wages of lower-quality workers. We think that the workerfirm interactions and the margin of firm responses highlighted in this paper are important to capture a full set of effects of immigration which are overlooked in a neoclassical model. 


\section{Bibliography}

Abowd, J. M., Kramarz, F. \& Margolis, D. N. (1999), ‘High Wage Workers and High Wage Firms', Econometrica 67(2), 251-334.

Acemoglu, D. (1999), 'Changes in Unemployment and Wage Inequality: An Alternative Theory and Some Evidence', American Economic Review 89(5), 1259-1278.

Albrecht, J. \& Vroman, S. (2002), 'A Matching Model with Endogenous Skill Requirements', International Economic Review 43(1), 283-305.

Autor, D. H., Dorn, D. \& Hanson, G. H. (2013), 'The China Syndrome: Local Labor Market Effects of Import Competition in the United States', American Economic Review 103(6), 2121-2168.

Bartolucci, C., Devicienti, F. \& Monzón, I. (2018), 'Identifying Sorting in Practice', American Economic Journal: Applied Economics 10(4), 408-438.

Battisti, M., Felbermayr, G., Peri, G. \& Poutvaara, P. (2018), 'Immigration, Search and Redistribution: A Quantitative Assessment of Native Welfare', Journal of the European Economic Association 16(4), 1137-1188.

Bernard, A. B., Jensen, J. B., Redding, S. J. \& Schott, P. K. (2007), 'Firms in International Trade', Journal of Economic Perspectives 21(3), 105-130.

Bombardini, M., Orefice, G. \& Tito, M. D. (2019), 'Does Exporting Improve Matching? Evidence from French Employer-Employee Data', Journal of International Economics 117, 229-241.

Borjas, G. J. (1987), 'Self-Selection and the Earnings of Immigrants', American Economic Review 77(4), 531-553.

Burzynski, M. \& Gola, P. (2019), Mexican Migration to the United States: Selection, Assignment, and Welfare, LISER Working Paper Series 2019-10, LISER.

Card, D. (2001), 'Immigrant Inflows, Native Outflows, and the Local Labor Market Impacts of Higher Immigration', Journal of Labor Economics 19(1), 22-64.

Card, D. (2005), 'Is the New Immigration Really so Bad?', Economic Journal 115(507), 300323.

Card, D., Cardoso, A. R., Heining, J. \& Kline, P. (2018), 'Firms and Labor Market Inequality: Evidence and Some Theory', Journal of Labor Economics 36(S1), 13-70.

Card, D., Heining, J. \& Kline, P. (2013), 'Workplace Heterogeneity and the Rise of West German Wage Inequality', The Quarterly Journal of Economics 128(3), 967-1015.

Chassamboulli, A. \& Palivos, T. (2014), 'A Search-Equilibrium Approach To The Effects Of Immigration On Labor Market Outcomes', International Economic Review 55, 111-129.

Combes, P.-P., Duranton, G. \& Gobillon, L. (2008), 'Spatial wage disparities: Sorting matters!', Journal of Urban Economics 63(2), 723-742. 
Conley, T. G., Hansen, C. B. \& Rossi, P. E. (2012), 'Plausibly Exogenous', The Review of Economics and Statistics 94(1), 260-272.

Dauth, W., Findeisen, S., Moretti, E. \& Suedekum, J. (2018), Matching in Cities, NBER Working Papers 25227, National Bureau of Economic Research, Inc.

Davidson, C., Heyman, F., Matusz, S., Sjoholm, F. \& Zhu, S. C. (2012), 'Liberalized Trade and Worker-Firm Matching', American Economic Review 102(3), 429-434.

Davidson, C., Heyman, F., Matusz, S., Sjoholm, F. \& Zhu, S. C. (2014), 'Globalization and imperfect labor market sorting', Journal of International Economics 94(2), 177-194.

Davidson, C., Matusz, S. J. \& Shevchenko, A. (2008), 'Globalization and firm level adjustment with imperfect labor markets', Journal of International Economics 75(2), 295-309.

De La Roca, J. \& Puga, D. (2017), 'Learning by Working in Big Cities', Review of Economic Studies 84(1), 106-142.

de Melo, R. L. (2018), 'Firm Wage Differentials and Labor Market Sorting: Reconciling Theory and Evidence', Journal of Political Economy 126(1), 313-346.

Dustmann, C., Frattini, T. \& Preston, I. P. (2013), 'The Effect of Immigration along the Distribution of Wages', Review of Economic Studies 80(1), 145-173.

Eeckhout, J. \& Kircher, P. (2011), 'Identifying Sorting-In Theory’, Review of Economic Studies 78(3), 872-906.

Eeckhout, J. \& Kircher, P. (2018), 'Assortative matching with large firms', Econometrica 86(1), 85-132.

Friedberg, R. M. \& Hunt, J. (1995), 'The Impact of Immigrants on Host Country Wages, Employment and Growth', Journal of Economic Perspectives 9(2), 23-44.

Gautier, P. A. \& Teulings, C. N. (2006), 'How Large are Search Frictions?', Journal of the European Economic Association 4(6), 1193-1225.

Glaeser, E. L. \& Mare, D. C. (2001), 'Cities and Skills', Journal of Labor Economics 19(2), 316-342.

Goldsmith-Pinkham, P., Sorkin, I. \& Swift, H. (2019), 'Bartik Instruments: What, When, Why, and How', American Economic Review (forthcoming).

Helpman, E., Itskhoki, O. \& Redding, S. (2010), 'Inequality and Unemployment in a Global Economy', Econometrica 78(4), 1239-1283.

Jaeger, D. A., Ruist, J. \& Stuhler, J. (2018), Shift-Share Instruments and the Impact of Immigration, NBER Working Papers 24285, National Bureau of Economic Research, Inc.

Kremer, M. (1993), 'The O-ring theory of economic development', The Quarterly Journal of Economics pp. pp. 551-575.

Lewis, E. \& Peri, G. (2015), Immigration and the Economy of Cities and Regions, in G. Duranton, J. V. Henderson \& W. C. Strange, eds, 'Handbook of Regional and Urban Economics', Vol. 5 of Handbook of Regional and Urban Economics, Elsevier, chapter 0 , 
pp. 625-685.

Mitaritonna, C., Orefice, G. \& Peri, G. (2017), 'Immigrants and firms? outcomes: Evidence from France', European Economic Review 96(C), 62-82.

Ottaviano, G. I. P. \& Peri, G. (2012), 'Rethinking The Effect Of Immigration On Wages’, Journal of the European Economic Association 10(1), 152-197.

Peri, G. (2012), 'The Effect Of Immigration On Productivity: Evidence From U.S. States', The Review of Economics and Statistics 94(1), 348-358.

Peri, G. \& Sparber, C. (2009), 'Task Specialization, Immigration, and Wages', American Economic Journal: Applied Economics 1(3), 135-169.

Pischke, J.-S. \& Velling, J. (1997), ‘Employment Effects Of Immigration To Germany: An Analysis Based On Local Labor Markets', The Review of Economics and Statistics 79(4), 594-604.

Wooldridge, J. M. (2009), 'On estimating firm-level production functions using proxy variables to control for unobservables', Economics Letters 104(3), 112-114. 


\section{Tables and Figures}

Table 1 - In-sample descriptive statistics.

\begin{tabular}{ccccc}
\hline \hline year & $\begin{array}{c}\text { \# workers } \\
\text { with ID }\end{array}$ & \# firms & \# movers & $\begin{array}{c}\text { Median } \\
\text { firm size }\end{array}$ \\
\hline 1996 & 92364 & 28115 & 739 & 198 \\
1997 & 92299 & 28417 & 3328 & 190 \\
1998 & 89982 & 27963 & 4359 & 190 \\
1999 & 89525 & 28058 & 4929 & 186 \\
2000 & 85748 & 27032 & 4746 & 194 \\
2001 & 86609 & 26969 & 6294 & 196 \\
2002 & 171263 & 39515 & 6717 & 192 \\
2003 & 163119 & 39263 & 5401 & 193 \\
2004 & 164486 & 38757 & 7674 & 187 \\
2005 & 166719 & 39066 & 9465 & 182 \\
\hline
\end{tabular}

Notes: In sample descriptive statistics on the number of workers with ID are based on DADS panel data. The number of firms and the number of movers are obtained after joining DADS panel and FICUS/FARE data. 
Figure 1 - Distribution of worker type (lifetime conditioned wage) by high- vs. lowproductivity firms.

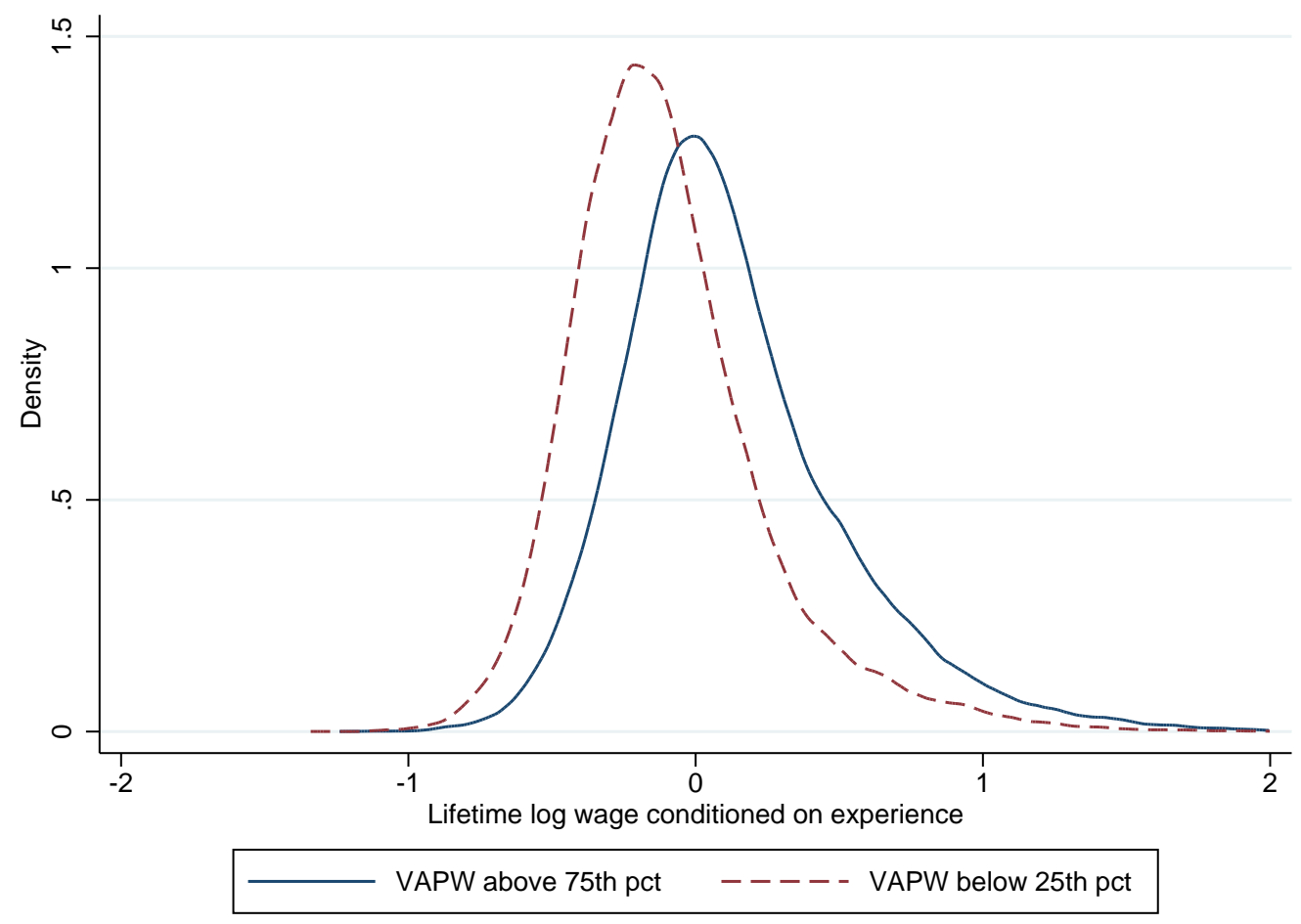

Source: Authors calculations on DADS and Ficus/Fare data. Note: The lifetime conditioned wage is the average wage earned by the worker over his/hers observed career (period 1995-2005). Worker's wage always purged by experience effect, seasonality (year fixed effects) and sector specificities (sector fixed effects). 
Figure 2 - Distribution of worker type (AKM decomposition) by high- vs. low-productivity firms.

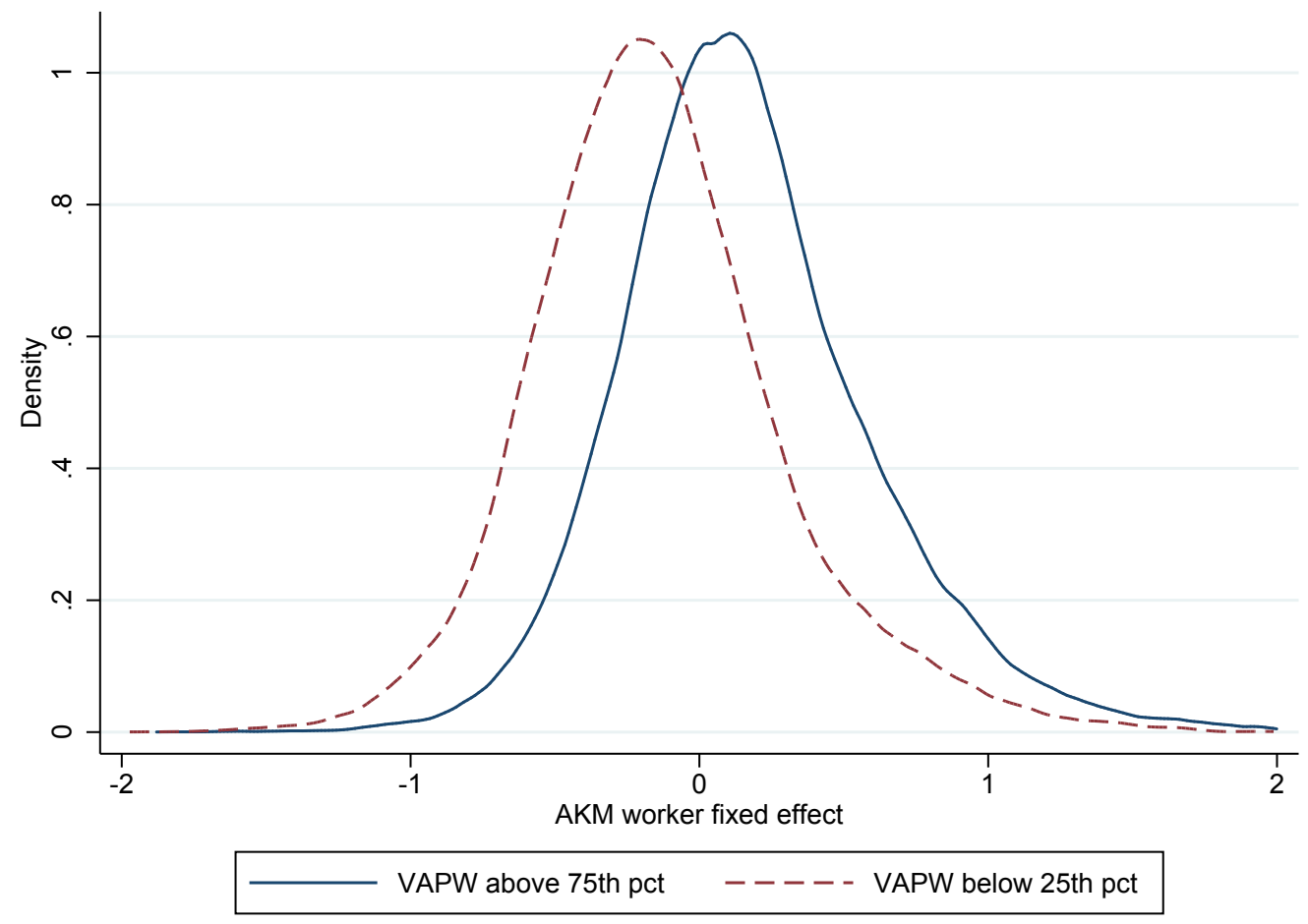

Source: Authors calculations on DADS and Ficus/Fare data. Note: Worker types are approximated here by worker fixed effects as estimated in equation 12. 
Table 2 - Share of workers of ability $i$ (with $i=$ high, low) employed at a firm with high vs low Value Added per worker. Worker ability: lifetime wage conditioned on experience. Top vs Bottom Immigrants intensive departments.

\begin{tabular}{|c|c|c|c|c|}
\hline & \multicolumn{4}{|c|}{ All Districts } \\
\hline & \multicolumn{2}{|c|}{ Year 1995} & \multicolumn{2}{|c|}{ Year 2005} \\
\hline & High-Prod Firms & Low-Prod Firms & High-Prod Firms & Low-Prod Firms \\
\hline High-Ability workers & $28.9 \%$ & $21.0 \%$ & $28.9 \%$ & $21.0 \%$ \\
\hline \multirow[t]{4}{*}{ Low-Ability workers } & $19.8 \%$ & $30.2 \%$ & $20.0 \%$ & $30.0 \%$ \\
\hline & \multicolumn{4}{|c|}{ High immigrants intensive Districts } \\
\hline & \multicolumn{2}{|c|}{ Year 1995} & \multicolumn{2}{|c|}{ Year 2005} \\
\hline & High-Prod Firms & Low-Prod Firms & High-Prod Firms & Low-Prod Firms \\
\hline High-Ability workers & $28.7 \%$ & $21.1 \%$ & $29.3 \%$ & $20.6 \%$ \\
\hline \multirow[t]{4}{*}{ Low-Ability workers } & $19.7 \%$ & $30.3 \%$ & $20.3 \%$ & $29.7 \%$ \\
\hline & \multicolumn{4}{|c|}{ Low immigrants intensive Districts } \\
\hline & \multicolumn{2}{|c|}{ Year 1995} & \multicolumn{2}{|c|}{ Year 2005} \\
\hline & High-Prod Firms & Low-Prod Firms & High-Prod Firms & Low-Prod Firms \\
\hline High-Ability workers & $29.1 \%$ & $20.7 \%$ & $28.7 \%$ & $21.2 \%$ \\
\hline Low-Ability workers & $20.0 \%$ & $30.1 \%$ & $19.7 \%$ & $30.3 \%$ \\
\hline
\end{tabular}

Notes: The calculations use the matched employer-employee French data provided by INSEE for the years 1995 and 2005. The classification of worker types in this table follows their lifetime wage (conditional on worker's experience), while Value Added per Worker is used as a proxy for the firm type. Each cell reports the percentage of workers of a given level of ability (high vs low) employed at a firm with high or low productivity. High- and low-type workers and firms refer respectively to workers and firm with type above and below the district average. The main diagonal represents the strength of assortative matching while the anti-diagonal represents the extent of mismatch in local labor market. The lifetime conditioned wage is the average wage earned by the worker over his/hers observed career (period 1995-2005). Worker's wage always purged by experience effect, seasonality (year fixed effects) and sector specificities (sector fixed effects). 
Table 3 - Empirical distribution characteristics for immigrant and native workers types

\begin{tabular}{llcc}
\hline \hline & & Natives & Immigrants \\
\hline \multirow{2}{*}{ Lifetime conditioned Wage } & Average & 0.01 & -0.01 \\
& Standard Deviation & 0.38 & 0.42 \\
& Interquartile Range & 0.43 & 0.46 \\
\hline \multirow{2}{*}{ AKM decomposition } & Average & 0.01 & -0.06 \\
& Standard Deviation & 0.45 & 0.53 \\
& Interquartile Range & 0.53 & 0.59 \\
\hline \hline
\end{tabular}

Notes: The lifetime conditioned wage is the average wage earned by the worker over his/hers observed career (period 1995-2005). Worker's wage always purged by experience effect, seasonality (year fixed effects) and sector specificities (sector fixed effects).

Table 4 - Immigrants and the distribution of workers types (as revealed by lifetime conditioned wage) across districts by moment of worker type distribution.

\begin{tabular}{lcccccc}
\hline \hline $\begin{array}{l}\text { Moment of worker } \\
\text { type distribution }\end{array}$ & $5^{\text {th }}$ pctile & $10^{\text {th }}$ pctile & $25^{\text {th }}$ pctile & $75^{\text {th }}$ pctile & $90^{\text {th }}$ pctile & $95^{\text {th }}$ pctile \\
\hline Immi Share & $-0.090^{* *}$ & $-0.080^{* *}$ & $-0.060^{* *}$ & $0.081^{* * *}$ & $0.255^{* * *}$ & 0.056 \\
& $(0.043)$ & $(0.033)$ & $(0.023)$ & $(0.027)$ & $(0.057)$ & $(0.082)$ \\
\hline Observations & 1,056 & 1,056 & 1,056 & 1,056 & 1,056 & 1,056 \\
\hline \hline
\end{tabular}

Note: All regressions include region-by-year fixed effects, the average worker type in the district, and the districtyear specific controls described in the empirical strategy. The lifetime conditioned wage is the average wage earned by the worker over his/hers observed career (period 1995-2005). Worker's wage always purged by experience effect, seasonality (year fixed effects) and sector specificities (sector fixed effects). Robust standard errors in parenthesis. $* * * p<0,01 ; * * p<0,05 ; * p<0,1$.

Table 5 - Strength of assortative matching and value added per worker in the district.

\begin{tabular}{|c|c|c|c|c|}
\hline & \multicolumn{4}{|c|}{ Value Added per worker } \\
\hline & $(1)$ & $(2)$ & (3) & (4) \\
\hline Rank Corr. VAPW-Lifetime Wage & $\begin{array}{c}0.198^{* * *} \\
(0.038)\end{array}$ & & & \\
\hline Rank Corr. VAPW-AKM & & $\begin{array}{c}0.196 * * * \\
(0.038)\end{array}$ & & \\
\hline Strength PAM VAPW-Lifetime Wage & & & $\begin{array}{c}0.144 * * * \\
(0.033)\end{array}$ & \\
\hline Strength PAM VAPW-AKM & & & & $\begin{array}{c}0.159 * * * \\
(0.029)\end{array}$ \\
\hline District FE & yes & yes & yes & yes \\
\hline Region-by-Year FE & yes & yes & yes & yes \\
\hline Observations & 1,056 & 1,056 & 1,054 & 1,048 \\
\hline R-squared & 0.998 & 0.998 & 0.998 & 0.998 \\
\hline
\end{tabular}

Note: Dependent variable is the average Value Added per Worker across firms within a district. All regressions include district and region-by-year fixed effects. The lifetime conditioned wage is the average wage earned by the worker over his/hers observed career (period 1995-2005). Worker's wage always purged by experience effect, seasonality (year fixed effects) and sector specificities (sector fixed effects). Robust standard errors in parenthesis. $* * * p<0,01 ; * * p<0,05 ; * p<0,1$. 
Figure 3 - Change in migrant population and Worker-Firm match across districts.

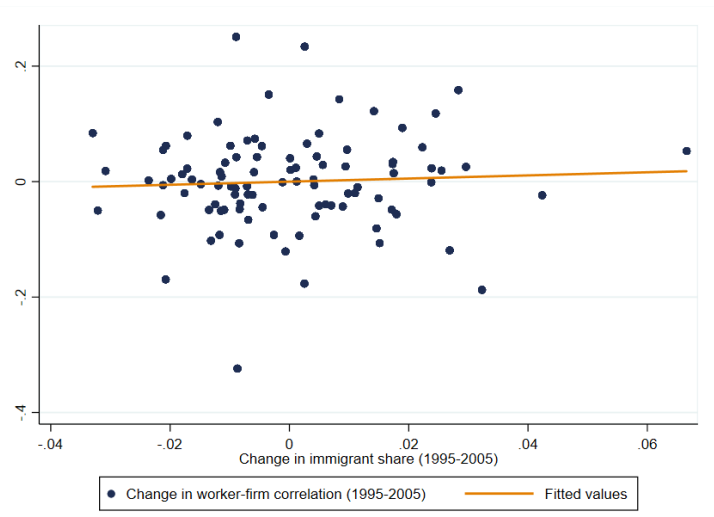

(a) Change in immigrant share and Worker-Firm type correlation. Worker type: lifetime conditional wage.

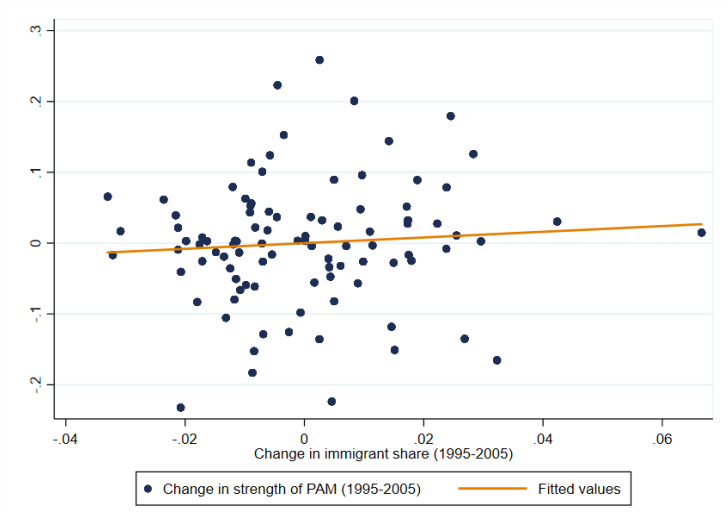

(c) Change in immigrant share and strength of PAS. Worker type: lifetime conditional wage.

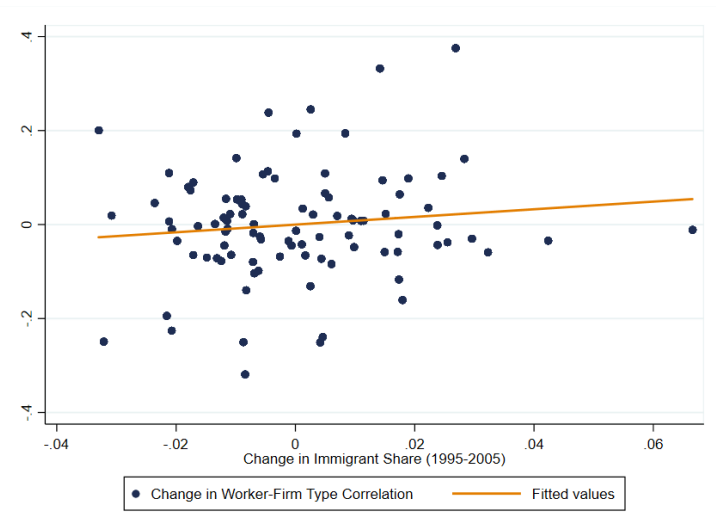

(b) Change in immigrant share and Worker-Firm type correlation. Worker type: AKM fixed effects.

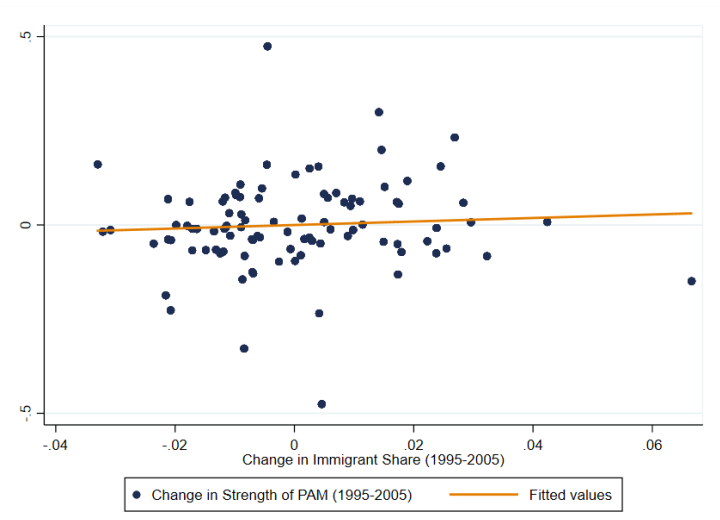

(d) Change in immigrant share and strength of PAS. Worker type: AKM fixed effects.

Note: Variables conditioned on region fixed effects

Source: Authors' calculation DADS data for the period 1995-2005.

Table $\mathbf{6}$ - Test for the validity of the Instrumental Variable.

\begin{tabular}{lcccccc}
\hline & $\Delta$ Emplo & $\Delta$ Wage & $\Delta$ Emplo & $\Delta$ Nat. Emp. & $\Delta$ Wage & $\Delta$ Wage Nat. \\
& $1995-1994$ & $1995-1994$ & $1990-1982$ & $1990-1982$ & $1990-1982$ & $1990-1982$ \\
\hline$\Delta$ IV (05-95) & 218.1 & -5.285 & -242.6 & -395.5 & -0.875 & -0.838 \\
& $(151.6)$ & $(8.455)$ & $(1080)$ & $(1010)$ & $(1.601)$ & $(1.696)$ \\
\hline Source & DADS & DADS & LFS & LFS & LFS & LFS \\
\hline Observations & 92 & 92 & 92 & 92 & 92 & 92 \\
R-squared & 0.552 & 0.414 & 0.302 & 0.306 & 0.749 & 0.746 \\
\hline
\end{tabular}

Notes: All regressions include region fixed effects. Difference in the average wage 1990-1982 form LFS data bases on difference in wage bin based on decile of hourly wage distribution. Robust standard errors in parenthesis. $* * *$ $p<0,01 ; * * p<0,05 ; * p<0,1$. 
Table 7 - Baseline regressions using Value Added per worker as proxy for firm type. OLS estimations

\begin{tabular}{|c|c|c|c|c|c|}
\hline \multirow[t]{2}{*}{ Dep Var: } & \multicolumn{2}{|c|}{ Rank Correlation } & \multicolumn{2}{|c|}{ Strength PAM } & \multirow{2}{*}{$\begin{array}{c}\text { Firm Profit } \\
(5)\end{array}$} \\
\hline & $(1)$ & $(2)$ & (3) & (4) & \\
\hline \multirow[t]{2}{*}{ Immi Share } & 0.440 & -0.013 & $0.931 * * *$ & -0.111 & 2.096 \\
\hline & $(0.290)$ & $(0.295)$ & $(0.265)$ & $(0.307)$ & $(1.959)$ \\
\hline \multirow[t]{2}{*}{ Employment (In) } & -0.086 & 0.012 & $-0.117^{* *}$ & 0.032 & $-0.936 * *$ \\
\hline & $(0.066)$ & $(0.069)$ & $(0.058)$ & $(0.063)$ & $(0.476)$ \\
\hline \multirow[t]{2}{*}{ Firms Concentration } & $1.846 * * *$ & $1.865 * * *$ & $1.653 * * *$ & $1.551 * * *$ & $18.078 * * *$ \\
\hline & $(0.437)$ & $(0.532)$ & $(0.383)$ & $(0.534)$ & $(3.742)$ \\
\hline \multirow[t]{2}{*}{ Skilled share } & 0.286 & -0.110 & $0.298 * *$ & -0.101 & 0.655 \\
\hline & $(0.185)$ & $(0.220)$ & $(0.151)$ & $(0.191)$ & $(1.030)$ \\
\hline Worker Type & $\begin{array}{l}\text { Lifetime } \\
\text { wage }\end{array}$ & $\mathrm{AKM}$ & $\begin{array}{l}\text { Lifetime } \\
\text { wage }\end{array}$ & $\mathrm{AKM}$ & \\
\hline District FE & yes & yes & yes & yes & yes \\
\hline Region-Year FE & yes & yes & yes & yes & yes \\
\hline Observations & 1,012 & 1,012 & 1,012 & 1,012 & 1,003 \\
\hline R-squared & 0.672 & 0.675 & 0.589 & 0.643 & 0.961 \\
\hline
\end{tabular}

Notes: Dependent variables are respectively the rank correlation between worker and firm type, the strength of positive assortative matching, and the average firms' profits in each district-year. District-year specific controls are: (i) number of workers in the district, (ii) concentration of firms and (iii) the share of skilled workers in the districts. The lifetime conditioned wage is the average wage earned by the worker over his/hers observed career (period 1995-2005). Worker's wage always purged by experience effect, seasonality (year fixed effects) and sector specificities (sector fixed effects). Robust standard errors in parenthesis. $* * * \quad p<0,01 ; * * p<0,05 ; * p<0,1$. 
Table 8 - Baseline regressions using Value Added per worker as proxy for firm type. 2SLS estimations

\begin{tabular}{|c|c|c|c|c|c|}
\hline \multirow[t]{2}{*}{ Dep Var: } & \multicolumn{2}{|c|}{ Rank Correlation } & \multicolumn{2}{|c|}{ Strength PAM } & \multirow{2}{*}{$\begin{array}{c}\text { Firm Profit } \\
(5)\end{array}$} \\
\hline & (1) & (2) & (3) & (4) & \\
\hline \multirow[t]{2}{*}{ Immi Share } & $2.423 * *$ & $5.105 * * *$ & $3.361 * * *$ & $4.718 * * *$ & $16.613^{* *}$ \\
\hline & $(1.191)$ & $(1.722)$ & $(1.184)$ & $(1.619)$ & $(7.560)$ \\
\hline \multirow[t]{2}{*}{ Employment (In) } & -0.081 & 0.025 & $-0.111 * *$ & 0.044 & $-0.886 * *$ \\
\hline & $(0.058)$ & $(0.068)$ & $(0.053)$ & $(0.067)$ & $(0.409)$ \\
\hline \multirow[t]{2}{*}{ Firms Concentration } & $1.880 * * *$ & $1.951 * * *$ & $1.694 * * *$ & $1.632 * * *$ & $18.320 * * *$ \\
\hline & $(0.391)$ & $(0.498)$ & $(0.339)$ & $(0.526)$ & $(3.064)$ \\
\hline \multirow[t]{2}{*}{ Skilled share } & $0.500 * *$ & $0.441^{*}$ & $0.560 * * *$ & $0.420^{*}$ & $2.237^{*}$ \\
\hline & $(0.197)$ & $(0.257)$ & $(0.183)$ & $(0.241)$ & $(1.167)$ \\
\hline Worker Type & $\begin{array}{l}\text { Lifetime } \\
\text { wage }\end{array}$ & $\mathrm{AKM}$ & $\begin{array}{l}\text { Lifetime } \\
\text { wage }\end{array}$ & $\mathrm{AKM}$ & \\
\hline District FE & yes & yes & yes & yes & yes \\
\hline Region-Year FE & yes & yes & yes & yes & yes \\
\hline Observations & 1,012 & 1,012 & 1,012 & 1,012 & 1,003 \\
\hline First stage coeff & $0.121 * * *$ & $0.121^{* * *}$ & $0.121^{* * *}$ & $0.121^{* * *}$ & $0.122 * * *$ \\
\hline F-stat & 16.18 & 16.18 & 16.18 & 16.18 & 15.00 \\
\hline Partial R-sq & 0.046 & 0.046 & 0.046 & 0.046 & 0.045 \\
\hline
\end{tabular}

Notes: Dependent variables are respectively the rank correlation between worker and firm type, the strength of positive assortative matching, and the average firms' profits in each district-year. District-year specific controls are: (i) number of workers in the district, (ii) concentration of firms and the (iii) share of skilled workers in the districts. The lifetime conditioned wage is the average wage earned by the worker over his/hers observed career (period 1995-2005). Worker's wage always purged by experience effect, seasonality (year fixed effects) and sector specificities (sector fixed effects). Robust standard errors in parenthesis. *** $p<0,01 ; * * p<0,05 ; * p<0,1$. 
Table 9 - Baseline regressions using Value Added per worker as proxy for firm type. Alternative IV, i.e. geographic distribution of immigrants across districts in 1982 augmented by the observed migration inflows in France by origin country (i.e. standard shift-share approach).

\begin{tabular}{|c|c|c|c|c|c|}
\hline \multirow[t]{2}{*}{ Dep Var: } & \multicolumn{2}{|c|}{ Rank Correlation } & \multicolumn{2}{|c|}{ Strength PAM } & \multirow{2}{*}{$\begin{array}{c}\text { Firm Profit } \\
(5)\end{array}$} \\
\hline & (1) & (2) & (3) & (4) & \\
\hline \multirow[t]{2}{*}{ Immi Share } & $2.896^{*}$ & 1.899 & $3.620 * *$ & $3.425 * *$ & $24.390 * *$ \\
\hline & $(1.511)$ & $(1.735)$ & $(1.540)$ & $(1.728)$ & $(12.413)$ \\
\hline \multirow[t]{2}{*}{ Employment (In) } & -0.080 & 0.017 & $-0.110 * *$ & 0.041 & $-0.860 * *$ \\
\hline & $(0.059)$ & $(0.059)$ & $(0.054)$ & $(0.060)$ & $(0.422)$ \\
\hline \multirow[t]{2}{*}{ Firms Concentration } & $1.888 * * *$ & $1.897 * * *$ & $1.698 * * *$ & $1.610^{* * *}$ & $18.449 * * *$ \\
\hline & $(0.396)$ & $(0.454)$ & $(0.344)$ & $(0.496)$ & $(3.099)$ \\
\hline \multirow[t]{2}{*}{ Skilled share } & $0.551^{* *}$ & 0.096 & $0.588 * * *$ & 0.280 & $3.085^{*}$ \\
\hline & $(0.230)$ & $(0.236)$ & $(0.225)$ & $(0.252)$ & $(1.663)$ \\
\hline Worker Type & $\begin{array}{l}\text { Lifetime } \\
\text { wage }\end{array}$ & $\mathrm{AKM}$ & $\begin{array}{l}\text { Lifetime } \\
\text { wage }\end{array}$ & $\mathrm{AKM}$ & \\
\hline District FE & yes & yes & yes & yes & yes \\
\hline Region-Year FE & yes & yes & yes & yes & yes \\
\hline Observations & 1,012 & 1,012 & 1,012 & 1,012 & 1,003 \\
\hline First stage coeff & $0.284^{* * *}$ & $0.284^{* * *}$ & $0.284^{* * *}$ & $0.284^{* * *}$ & $0.278^{* * *}$ \\
\hline F-stat & 9.29 & 9.29 & 9.29 & 9.29 & 8.58 \\
\hline Partial R-sq & 0.031 & 0.031 & 0.031 & 0.031 & 0.030 \\
\hline
\end{tabular}

Notes: Dependent variables are respectively the rank correlation between worker and firm type, the strength of positive assortative matching, and the average firms' profits in each district-year. District-year specific controls are: (i) number of workers in the district, (ii) concentration of firms and (iii) the share of skilled workers in the districts. The lifetime conditioned wage is the average wage earned by the worker over his/hers observed career (period 1995-2005). Worker's wage always purged by experience effect, seasonality (year fixed effects) and sector specificities (sector fixed effects). Robust standard errors in parenthesis. *** $p<0,01 ; * * p<0,05 ; * p<0,1$. 
Table 10 - Robustness check controlling for the total exports, capital intensity and intermediate inputs intensity in each district. 2SLS estimations

\begin{tabular}{|c|c|c|c|c|c|}
\hline \multirow[t]{2}{*}{ Dep Var: } & \multicolumn{2}{|c|}{ Rank Correlation } & \multicolumn{2}{|c|}{ Strength PAM } & \multirow{2}{*}{$\begin{array}{c}\text { Firm Profit } \\
(5)\end{array}$} \\
\hline & $(1)$ & $(2)$ & $(3)$ & (4) & \\
\hline \multirow[t]{2}{*}{ Immi Share } & $2.877^{* *}$ & $4.776^{* * *}$ & $3.299 * * *$ & $4.583^{* * *}$ & $22.043 * * *$ \\
\hline & $(1.136)$ & $(1.564)$ & $(1.090)$ & $(1.473)$ & $(7.644)$ \\
\hline \multirow[t]{2}{*}{ Employment (In) } & -0.078 & 0.017 & $-0.117 * *$ & 0.048 & $-0.880 * *$ \\
\hline & $(0.059)$ & $(0.066)$ & $(0.053)$ & $(0.065)$ & $(0.422)$ \\
\hline \multirow[t]{2}{*}{ Firms Concentration } & $1.544 * * *$ & $1.496 * *$ & $1.946 * * *$ & 0.830 & $7.676 * * *$ \\
\hline & $(0.530)$ & $(0.620)$ & $(0.425)$ & $(0.653)$ & $(2.482)$ \\
\hline \multirow[t]{2}{*}{ Skilled share } & $0.555 * * *$ & $0.431^{*}$ & $0.556 * * *$ & $0.421^{*}$ & $3.245^{* * *}$ \\
\hline & $(0.200)$ & $(0.244)$ & $(0.180)$ & $(0.230)$ & $(1.175)$ \\
\hline \multirow[t]{2}{*}{ Exports } & 0.010 & 0.013 & -0.006 & $0.021 * * *$ & $0.301 * * *$ \\
\hline & $(0.007)$ & $(0.008)$ & $(0.006)$ & $(0.008)$ & $(0.039)$ \\
\hline \multirow[t]{2}{*}{$K / L$} & -0.002 & $-0.007 * *$ & -0.001 & -0.004 & $-0.099 * * *$ \\
\hline & $(0.002)$ & $(0.003)$ & $(0.002)$ & $(0.003)$ & $(0.026)$ \\
\hline \multirow[t]{2}{*}{ Intermediates/Tot Prod } & 0.006 & -0.002 & 0.003 & $-0.006^{*}$ & $0.083 * * *$ \\
\hline & $(0.004)$ & $(0.003)$ & $(0.003)$ & $(0.003)$ & $(0.024)$ \\
\hline Worker Type & $\begin{array}{l}\text { Lifetime } \\
\text { wage }\end{array}$ & $\mathrm{AKM}$ & $\begin{array}{l}\text { Lifetime } \\
\text { wage }\end{array}$ & $\mathrm{AKM}$ & \\
\hline \multirow{2}{*}{$\begin{array}{l}\text { District FE } \\
\text { Region-Year FE }\end{array}$} & yes & yes & yes & yes & yes \\
\hline & yes & yes & yes & yes & yes \\
\hline Observations & 1,012 & 1,012 & 1,012 & 1,012 & 1,003 \\
\hline First stage coeff & $0.135 * * *$ & $0.135 * * *$ & $0.135 * * *$ & $0.135^{* * *}$ & $0.136 * * *$ \\
\hline F-stat & 20.64 & 20.64 & 20.64 & 20.64 & 19.17 \\
\hline Partial R-sq & 0.053 & 0.053 & 0.053 & 0.053 & 0.052 \\
\hline
\end{tabular}

Notes: Dependent variables are respectively the rank correlation between worker and firm type, the strength of positive assortative matching, and the average firms' profits in each district-year. District-year specific controls are: (i) number of workers in the district, (ii) concentration of firms, (iii) share of skilled workers in the districts, (iv) total exports of firms in the district, (v) average capital intensity of firms in the district, and (vi) the average intermediate input intensity of firms in the district. The lifetime conditioned wage is the average wage earned by the worker over his/hers observed career (period 1995-2005). Worker's wage always purged by experience effect, seasonality (year fixed effects) and sector specificities (sector fixed effects). Robust standard errors in parenthesis. $* * * p<0,01 ; * * p<0,05 ; * p<0,1$. 
Table 11 - Native vs. Migrant workers assortative matching. Regressions using Value Added per worker as proxy for firm type. 2SLS estimations.

\begin{tabular}{|c|c|c|c|c|}
\hline \multirow[t]{2}{*}{ Dep Var: } & \multicolumn{2}{|c|}{ Rank Correlation } & \multicolumn{2}{|c|}{ Strength PAM } \\
\hline & $(1)$ & $(2)$ & (3) & $(4)$ \\
\hline \multicolumn{5}{|c|}{ Native workers only } \\
\hline Immi Share & $\begin{array}{c}2.495^{* *} \\
(1.262)\end{array}$ & $\begin{array}{c}5.667^{* * *} \\
(1.791)\end{array}$ & $\begin{array}{c}2.590 * * \\
(1.161)\end{array}$ & $\begin{array}{c}4.358^{* * *} \\
(1.598)\end{array}$ \\
\hline Observations & 1,012 & 1,012 & 1,012 & 1,012 \\
\hline First stage coeff & $0.120 * * *$ & $0.120 * * *$ & $0.120 * * *$ & $0.120 * * *$ \\
\hline F-stat & 16.18 & 16.18 & 16.18 & 16.18 \\
\hline Partial R-sq & 0.046 & 0.046 & 0.046 & 0.046 \\
\hline \multicolumn{5}{|c|}{ Migrant workers only } \\
\hline Immi Share & $\begin{array}{l}4.723^{*} \\
(2.459)\end{array}$ & $\begin{array}{c}5.401^{* *} \\
(2.735)\end{array}$ & $\begin{array}{c}9.356 * * * \\
(3.016)\end{array}$ & $\begin{array}{c}11.263^{* * *} \\
(3.532)\end{array}$ \\
\hline Observations & 1,012 & 1,012 & 1,005 & 1,005 \\
\hline First stage coeff & $0.120 * * *$ & $0.120 * * *$ & $0.117^{* * *}$ & $0.117^{* * *}$ \\
\hline F-stat & 16.18 & 16.18 & 15.05 & 15.05 \\
\hline Partial R-sq & 0.046 & 0.046 & 0.042 & 0.042 \\
\hline Worker Type & $\begin{array}{c}\text { Lifetime } \\
\text { wage }\end{array}$ & $\mathrm{AKM}$ & $\begin{array}{c}\text { Lifetime } \\
\text { wage }\end{array}$ & $\mathrm{AKM}$ \\
\hline District FE & yes & yes & yes & yes \\
\hline Region-Year FE & yes & yes & yes & yes \\
\hline District controls & yes & yes & yes & yes \\
\hline
\end{tabular}

Notes: Dependent variables are respectively the rank correlation between native/migrant worker and firm type and the strength of positive assortative matching in each district-year. District-year specific controls are: (i) number of workers in the district, (ii) concentration of firms and (iii) the share of skilled workers in the districts. The lifetime conditioned wage is the average wage earned by the worker over his/hers observed career (period 1995-2005). Worker's wage always purged by experience effect, seasonality (year fixed effects) and sector specificities (sector fixed effects). Robust standard errors in parenthesis. *** $p<0,01 ; * * p<0,05 ; * p<0,1$. 
Table 12 - Wage inequality regressions. Dependent variable: difference in log wage between high- and low-type workers (i.e. workers with type above and below the average in the district). 2SLS estimations.

\begin{tabular}{lcccc}
\hline \hline Dep Var: & \multicolumn{4}{c}{$L n($ wage } \\
\cline { 2 - 5 } & $(1)$ & $(2)$ & $(3)$ & $(4)$ \\
\hline Immi Sha & $-L n($ wage \\
& $1.682^{* *}$ & $1.886^{* *}$ & $2.107^{* *}$ & $2.143^{* *}$ \\
& $(0.790)$ & $(0.760)$ & $(0.908)$ & $(0.838)$ \\
\hline Worker Type & \multicolumn{2}{c}{ Lifetime wage } & \multicolumn{2}{c}{ AKM } \\
\hline District FE & yes & yes & yes & yes \\
Region-Year FE & yes & yes & yes & yes \\
District controls & yes & yes & yes & yes \\
Other district controls & no & yes & no & yes \\
\hline Observations & 1,012 & 1,012 & 1,012 & 1,012 \\
\hline First stage coeff & $0.120^{* * *}$ & $0.135^{* * *}$ & $0.120^{* * *}$ & $0.135^{* * *}$ \\
F-stat & 16.18 & 20.64 & 16.18 & 20.64 \\
\hline
\end{tabular}

Notes: Dependent variable is the difference in (log) average wage between high- and low-type workers in each district-year. District-year specific controls always included are: number of workers in the district, concentration of firms and the share of skilled workers in the districts. Other district specific controls included in columns 2 and 4 are: (i) district's total exports, (ii) average capital intensity, and (iii) intermediate inputs intensity. The lifetime conditioned wage is the average wage earned by the worker over his/hers observed career (period 1995-2005). Worker's wage always purged by experience effect, seasonality (year fixed effects) and sector specificities (sector fixed effects). Robust standard errors in parenthesis. *** $p<0,01 ; * * p<0,05 ; * p<0,1$. 


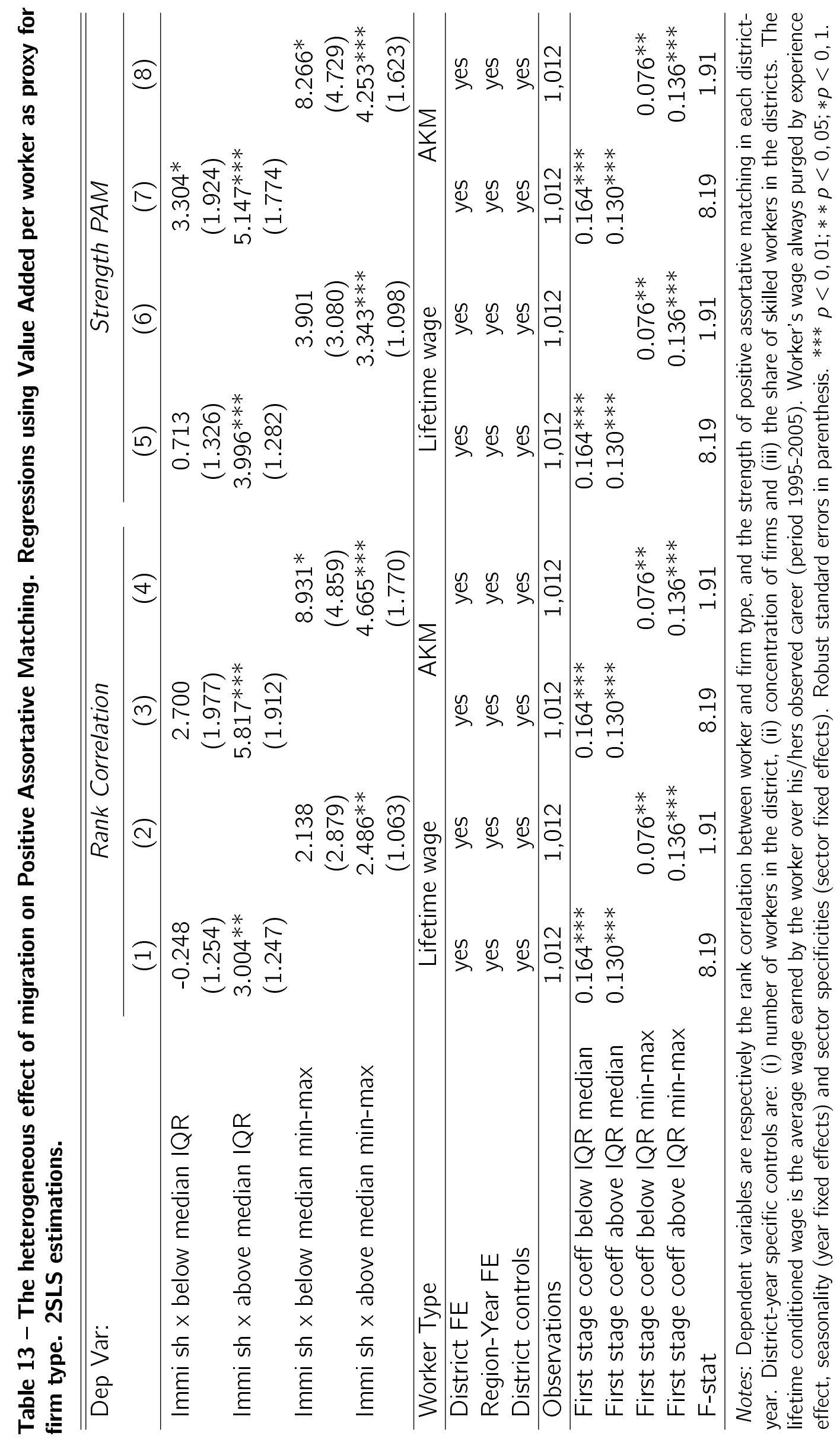


Table 14 - Number of movers by worker-type across firms of different type. Firm type based on value added per worker above (high type) or below (low type) the median. 2SLS estimations.

\begin{tabular}{|c|c|c|}
\hline & \multicolumn{2}{|c|}{ \# High-type movers } \\
\hline & $\begin{array}{l}\text { from low to high } \\
\text { type firm } \\
(1)\end{array}$ & $\begin{array}{c}\text { from high to low } \\
\text { type firm } \\
(2)\end{array}$ \\
\hline \multirow[t]{4}{*}{ Immi Share } & $31.126 * * *$ & 18.690 \\
\hline & $(12.790)$ & $(11.570)$ \\
\hline & \multicolumn{2}{|c|}{ \# Low-type movers } \\
\hline & $\begin{array}{c}\text { from high to low } \\
\text { type firm } \\
\text { (1) }\end{array}$ & $\begin{array}{l}\text { from low to high } \\
\text { type firm } \\
\text { (2) }\end{array}$ \\
\hline \multirow[t]{2}{*}{ Immi Share } & $36.544 * * *$ & 8.036 \\
\hline & $(13.635)$ & $(11.564)$ \\
\hline Worker Type & \multicolumn{2}{|c|}{ Lifetime } \\
\hline Firm Type & \multicolumn{2}{|c|}{ Value Added per Worker } \\
\hline District FE & yes & yes \\
\hline Region-Year FE & yes & yes \\
\hline District-Year controls & yes & yes \\
\hline Observations & 1,012 & 1,012 \\
\hline First stage coeff & \multicolumn{2}{|c|}{$0.120 * * *$} \\
\hline F-stat & \multicolumn{2}{|c|}{16.18} \\
\hline Partial R-squared & \multicolumn{2}{|c|}{0.046} \\
\hline
\end{tabular}

Notes: Dependent variables are the number of high- and low-type worker (in log) changing employer (i.e. siren code) and moving across firms of different type. High (low) type firms are firms with value added per worker above (below) the median. District-year specific controls are: number of workers in the district, concentration of firms and the share of skilled workers in the districts. The lifetime conditioned wage used to approximate the worker type is the average wage earned by the worker over his/hers observed career (period 1995-2005). Worker's wage always purged by experience effect, seasonality (year fixed effects) and sector specificities (sector fixed effects). Robust standard errors in parenthesis. $* * * p<0,01 ; * * p<0,05 ; * p<0,1$. 


\section{Appendix}

\section{Appendix tables}

Table A1 - Immigrants and the distribution of workers types (as revealed by lifetime conditioned wage) across districts.

\begin{tabular}{lccc}
\hline \hline & Std Dev & Inter-quartile & Min-Max diff. \\
& Worker Type & Worker Type & Worker Type \\
\hline Immi Share & $0.082^{* *}$ & $0.261^{* * *}$ & $2.434^{* * *}$ \\
& $(0.035)$ & $(0.061)$ & $(0.909)$ \\
\hline Observations & 1,056 & 1,056 & 1,056 \\
\hline \hline
\end{tabular}

Note: All regressions include region-by-year fixed effects and the districtyear specific controls described in the empirical strategy. The lifetime conditioned wage is the average wage earned by the worker over his/hers observed career (period 1995-2005). Worker's wage always purged by experience effect, seasonality (year fixed effects) and sector specificities (sector fixed effects). Robust standard errors in parenthesis. *** $p<0,01 ; * * p<0,05 ; * p<0,1$. 


\section{Figure A1 - Total employment and Positive Assortative Matching across districts.}

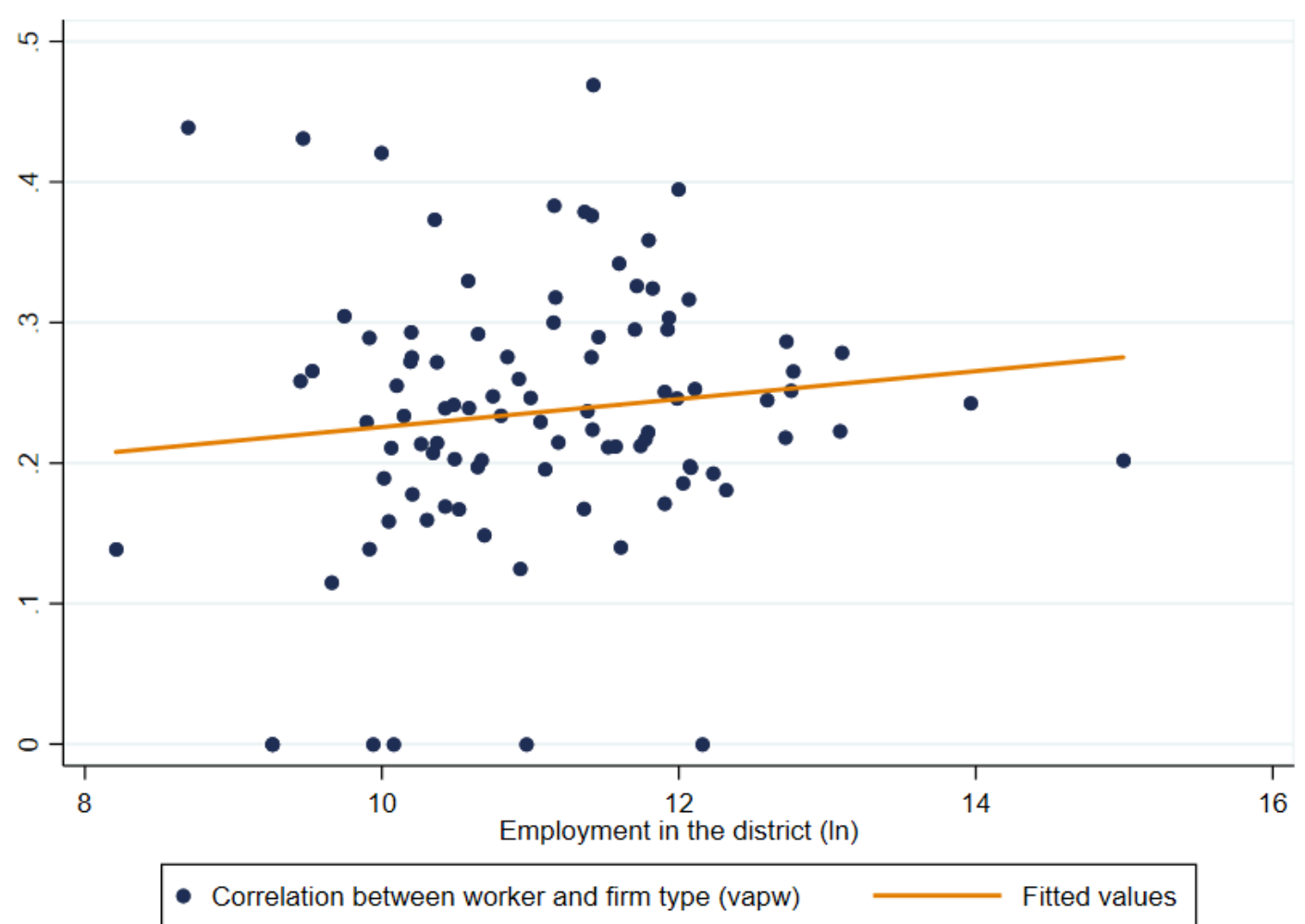

Source: Authors calculations on DADS and Ficus/Fare data. Note: Positive Assortative Matching approximated with the rank correlation between worker and firm type within a district. Worker type approximated by conditioned lifetime wage. Firm type approximated by value added per worker. The lifetime conditioned wage is the average wage earned by the worker over his/hers observed career (period 1995-2005).

Worker's wage always purged by experience effect, seasonality (year fixed effects) and sector specificities (sector fixed effects). 
Table A2 - Baseline regressions using Value Added per worker as proxy for firm type. Weighted OLS and 2SLS estimations (weights are the number of firms in the district as a share of total French firms)

\begin{tabular}{|c|c|c|c|c|c|}
\hline \multirow[t]{2}{*}{ Dep Var: } & \multicolumn{2}{|c|}{ Rank Correlation } & \multicolumn{2}{|c|}{ Strength PAM } & \multirow{2}{*}{$\frac{\text { Firm Profit }}{(5)}$} \\
\hline & (1) & $(2)$ & (3) & (4) & \\
\hline & \multicolumn{5}{|c|}{ Weighted OLS } \\
\hline \multirow[t]{3}{*}{ Immi Share } & $0.471^{* *}$ & -0.261 & $0.590 * * *$ & -0.034 & 2.006 \\
\hline & $(0.207)$ & $(0.243)$ & $(0.204)$ & $(0.279)$ & $(2.137)$ \\
\hline & \multicolumn{5}{|c|}{ Weighted 2SLS } \\
\hline \multirow[t]{2}{*}{ Immi Share } & $1.754^{* *}$ & $3.392 * *$ & $1.634 * *$ & $3.537 * *$ & 12.639 \\
\hline & $(0.774)$ & $(1.540)$ & $(0.716)$ & $(1.549)$ & $(8.091)$ \\
\hline Worker Type & $\begin{array}{l}\text { Lifetime } \\
\text { wage }\end{array}$ & $\mathrm{AKM}$ & $\begin{array}{l}\text { Lifetime } \\
\text { wage }\end{array}$ & $\mathrm{AKM}$ & \\
\hline District FE & yes & yes & yes & yes & yes \\
\hline Region-Year FE & yes & yes & yes & yes & yes \\
\hline District controls & yes & yes & yes & yes & yes \\
\hline Observations & 1,012 & 1,012 & 1,012 & 1,012 & 1,003 \\
\hline
\end{tabular}

Notes: Dependent variables are respectively the rank correlation between worker and firm type, the strength of positive assortative matching, and the average firms' profits in each district-year. District-year specific controls are: (i) number of workers in the district, (ii) concentration of firms and (iii) the share of skilled workers in the districts. The lifetime conditioned wage is the average wage earned by the worker over his/hers observed career (period 1995-2005). Worker's wage always purged by experience effect, seasonality (year fixed effects) and sector specificities (sector fixed effects). Robust standard errors in parenthesis. $* * * p<0,01 ; * * p<0,05 ; * p<0,1$. 
Table A3 - Robustness check using firm fixed effects from AKM decomposition as a proxy for firm type. 2SLS estimations.

\begin{tabular}{lccccc}
\hline \hline Dep Var: & \multicolumn{2}{c}{ Rank Correlation } & & \multicolumn{2}{c}{ Strength PAM } \\
\cline { 2 - 3 } \cline { 5 - 6 } & $(1)$ & $(2)$ & & $(3)$ & $(4)$ \\
\hline & 0.708 & $1.800^{* * *}$ & & 0.132 & $1.670^{*}$ \\
& $(1.231)$ & $(0.669)$ & & $(0.956)$ & $(0.939)$ \\
\hline Immi Share & yes & yes & yes & yes \\
& yes & yes & yes & yes \\
Region-Year FE & yes & yes & yes & yes \\
District controls & \multicolumn{5}{c}{$0.135^{* * *}$} \\
First stage coeff & \multicolumn{5}{c}{20.64} \\
F-stat
\end{tabular}

\begin{tabular}{lcccc}
\hline & \multicolumn{4}{c}{ Pooled specification } \\
\hline Immi Share & $1.284^{* * *}$ & $0.997^{* * *}$ & $0.713^{* * *}$ & 0.153 \\
& $(0.272)$ & $(0.291)$ & $(0.256)$ & $(0.325)$ \\
\hline District FE & no & no & no & no \\
Region-Year FE & yes & yes & yes & yes \\
District controls & yes & yes & yes & yes \\
\hline First stage coeff & \multicolumn{5}{c}{$0.174^{* * *}$} \\
F-stat & Lifetime & AKM & Lifetime & AKM \\
Worker Type & wage & \multicolumn{4}{c}{ wage } \\
& 1,012 & 1,012 & 1,012 & 1,012 \\
\hline Observations & &
\end{tabular}

Notes: Dependent variables are respectively the rank correlation between worker and firm type and the strength of positive assortative matching in each district-year. District-year specific controls are: (i) number of workers in the district, (ii) concentration of firms, (iii) share of skilled workers in the districts. The lifetime conditioned wage is the average wage earned by the worker over his/hers observed career (period 1995-2005). Worker's wage always purged by experience effect, seasonality (year fixed effects) and sector specificities (sector fixed effects). Robust standard errors in parenthesis. *** $p<0,01 ; * * p<0,05 ; * p<0,1$. 
Table A4 - Robustness check using alternative proxies for firm and worker type. 2SLS estimations.

\begin{tabular}{|c|c|c|c|c|}
\hline \multirow[t]{2}{*}{ Dep Var: } & \multicolumn{2}{|c|}{ Rank Correlation } & \multicolumn{2}{|c|}{ Strength PAM } \\
\hline & $(1)$ & $(2)$ & (3) & $(4)$ \\
\hline & \multicolumn{4}{|c|}{ Co-worker type as proxy for firm type } \\
\hline \multirow[t]{3}{*}{ Immi Share } & 0.446 & $19.988 * * *$ & 0.598 & $2.671^{* * *}$ \\
\hline & $(4.483)$ & $(5.402)$ & $(0.522)$ & $(0.715)$ \\
\hline & \multicolumn{4}{|c|}{ TFP as proxy for firm type } \\
\hline \multirow[t]{3}{*}{ Immi Share } & 1.129 & 0.408 & $1.659 *$ & 0.076 \\
\hline & $(1.192)$ & $(1.175)$ & $(0.863)$ & $(0.977)$ \\
\hline & \multicolumn{4}{|c|}{ Worker type conditioned on worker's occupation } \\
\hline \multirow[t]{2}{*}{ Immi Share } & 0.025 & 0.566 & 0.690 & $2.532 * * *$ \\
\hline & $(0.968)$ & $(1.124)$ & $(1.013)$ & $(0.915)$ \\
\hline District FE & yes & yes & yes & yes \\
\hline Region-Year FE & yes & yes & yes & yes \\
\hline District controls & yes & yes & yes & yes \\
\hline First stage coeff & \multicolumn{4}{|c|}{$0.135 * * *$} \\
\hline F-stat & \multicolumn{4}{|c|}{20.64} \\
\hline Worker Type & Lifetime & AKM & Lifetime & AKM \\
\hline & wage & & wage & \\
\hline Observations & 1,012 & 1,012 & 1,012 & 1,012 \\
\hline
\end{tabular}

Notes: Dependent variables are respectively the rank correlation between worker and firm type and the strength of positive assortative matching in each districtyear. District-year specific controls are: (i) number of workers in the district, (ii) concentration of firms, (iii) share of skilled workers in the districts, (iv) total export of firms in the district, (v) average capital and (iv) intermediates intensity of firms in the district. The lifetime conditioned wage is the average wage earned by the worker over his/hers observed career (period 1995-2005). Worker's wage always purged by experience effect, seasonality (year fixed effects) and sector specificities (sector fixed effects). Robust standard errors in parenthesis. *** $p<0,01 ; * * p<$ 0,$05 ; * p<0,1$. 
Table A5 - Robustness check excluding micro and very large firms from the calculation of the rank correlation and the strength of PAM. 2SLS estimations.

\begin{tabular}{lccccc}
\hline \hline Dep Var: & \multicolumn{2}{c}{ Rank Correlation } & & \multicolumn{2}{c}{ Strength PAM } \\
\cline { 2 - 3 } \cline { 5 - 6 } & $(1)$ & $(2)$ & & $(3)$ & $(4)$ \\
\hline Immi Share & $2.962^{* *}$ & $5.146^{* * *}$ & & $4.963^{* * *}$ & $3.815^{* * *}$ \\
& $(1.429)$ & $(1.722)$ & & $(1.635)$ & $(1.334)$ \\
Employment $($ In $)$ & -0.001 & 0.108 & & -0.083 & 0.088 \\
& $(0.066)$ & $(0.072)$ & & $(0.059)$ & $(0.060)$ \\
Firms Concentration & $2.127^{* * *}$ & $3.012^{* * *}$ & & $2.146^{* * *}$ & $2.255^{* * *}$ \\
& $(0.450)$ & $(0.522)$ & & $(0.413)$ & $(0.475)$ \\
Skilled share & $0.518^{* *}$ & 0.211 & & $0.558^{* *}$ & 0.253 \\
& $(0.226)$ & $(0.252)$ & & $(0.224)$ & $(0.220)$ \\
\hline Worker Type & Lifetime & AKM & & Lifetime & AKM \\
& wage & & & wage & \\
\hline District FE & yes & yes & & yes & yes \\
Region-Year FE & yes & yes & & yes & yes \\
\hline Observations & 1,012 & 1,012 & & 1,012 & 1,012 \\
\hline First stage coeff & $0.121^{* * *}$ & $0.121^{* * *}$ & & $0.121^{* * *}$ & $0.121^{* * *}$ \\
F-stat & 16.18 & 16.18 & & 16.18 & 16.18 \\
Partial R-sq & 0.046 & 0.046 & & 0.046 & 0.046 \\
\hline
\end{tabular}

Notes: Dependent variables are respectively the rank correlation between worker and firm type and the strength of positive assortative matching in each district-year. District-year specific controls are: (i) number of workers in the district, (ii) concentration of firms, (iii) share of skilled workers in the districts. The lifetime conditioned wage is the average wage earned by the worker over his/hers observed career (period 1995-2005). Worker's wage always purged by experience effect, seasonality (year fixed effects) and sector specificities (sector fixed effects). Robust standard errors in parenthesis. *** $p<0,01 ; * * p<0,05 ; * p<0,1$.

Table A6 - Estimated impact of immigrants share on assortative matching with plausibly exogenous instrument.

\begin{tabular}{|c|c|c|c|c|}
\hline \multirow[b]{2}{*}{ Dep Var } & \multicolumn{4}{|c|}{ Local-to-Zero estimations } \\
\hline & $\gamma$ & Coeff & $\begin{array}{c}\text { Min } \\
95 \% \mathrm{Cl}\end{array}$ & $\begin{array}{c}\text { Max } \\
95 \% \mathrm{Cl}\end{array}$ \\
\hline Rank Correlation Lifetime Wage VAPW & 0.25 & $2.423^{* *}$ & - & - \\
\hline Rank Correlation AKM worker FE VAPW & $0.64 * * *$ & $5.105 * * *$ & 0.058 & 11.206 \\
\hline Strength Matching Lifetime Wage VAPW & $0.30 * *$ & $3.361 * * *$ & 0.330 & 6.779 \\
\hline Strength Matching AKM worker FE VAPW & $0.60 * * *$ & $4.718 * * *$ & 0.017 & 10.473 \\
\hline
\end{tabular}


Table A7 - Number of movers by worker-type across firms of different types. High (low) type firms are firms with value added per worker above (below) the median.

\begin{tabular}{|c|c|c|c|c|}
\hline \multirow[b]{2}{*}{ year } & \multicolumn{2}{|c|}{ \# High-type movers across firms } & \multicolumn{2}{|c|}{ \# Low-type movers across firms } \\
\hline & $\begin{array}{l}\text { from low to high } \\
\text { type firm }\end{array}$ & $\begin{array}{c}\text { from high to low } \\
\text { type firm }\end{array}$ & $\begin{array}{c}\text { from high to low } \\
\text { type firm }\end{array}$ & $\begin{array}{c}\text { from low to high } \\
\text { type firm }\end{array}$ \\
\hline 1996 & 52 & 60 & 69 & 45 \\
\hline 1997 & 375 & 191 & 144 & 310 \\
\hline 1998 & 354 & 233 & 172 & 300 \\
\hline 1999 & 303 & 283 & 232 & 259 \\
\hline 2000 & 359 & 217 & 274 & 273 \\
\hline 2001 & 438 & 343 & 274 & 349 \\
\hline 2002 & 397 & 316 & 226 & 362 \\
\hline 2003 & 306 & 249 & 325 & 207 \\
\hline 2004 & 565 & 434 & 294 & 437 \\
\hline 2005 & 490 & 488 & 500 & 410 \\
\hline
\end{tabular}




\section{AKM decomposition orthogonality conditions and results}

As explained in the data section, we use use worker fixed effects from AKM decomposition as an additional proxy for worker type. To this end, we employ longitudinal matched employeremployee data (DADS panel) to estimate the standard mincerian wage equation as in AKM:

$$
\ln (\text { wage })_{i, t}=\alpha_{i}+\Phi_{\mathrm{J}(i, t)}+X_{i, t}+r_{i, t}
$$

where $\ln (\text { wage })_{i, t}$ is the log annual wage of worker $i$ at time $y ; \Phi_{\mathrm{J}(i, t)}$ is a firm fixed effects (representing the firm specific component in standard additive wage setting equation), $\alpha_{i}$ is a set of worker fixed effects that we will use as proxy for the worker type and $X_{i, t}$ is a set of worker-time controls capturing life-cycle and other aggregate factors that affect the wage of workers with specific characteristics (i.e. experience) in a given geographic area (i.e. Ile di France). Namely, the set of observable characteristics $\left(X_{i, t}\right)$ includes the quartic polynomial in experience, Ile-de-France dummy, department of residence dummy, gender interacted with experience, Ile-de-France, and year dummies. The error term $r_{i, t}$ consists of three separate random effects: (i) a match component $\eta_{i J(i, t)}$ representing the idiosyncratic wage surplus earned by the worker $i$ when matches a specific firm $j$, (ii) a unit root component $\epsilon_{i t}$ representing the time-varying component of the individual-specific earning power (such as human capital accumulation, health shocks, etc), and (iii) the pure idiosyncratic individual wage component $\epsilon_{i t}$.

To estimate equation (18) we follow Card et al. (2013) and adopt an iterative conjugate gradient algorithm. The correct identification of the OLS coefficients for $\alpha_{i}, \Phi_{\mathrm{J}(i, t)}$ and $X_{i, t}$ bases on their orthogonality with respect the error component $r_{i, t}$. The orthogonality between individual fixed effects, time-varying covariates and the error component is standard and widely recognized as valid. However, the orthogonality condition between the firm fixed effect and the three components of the error term must be discussed and verified. In other 
words, for a proper identification of equation (18) we need exogenous mobility.

To this end, we follow Card et al. (2013) and perform an event study analysis of the effect of job changes on wages (see section IV.B in Card et al.2013). This proceeds in four steps. First, for each individual $i$ at time $t$ we calculate the average co-worker wage. Second, for each job changer (or mover) with at least two-year employment spell in the new employer we classify the quartile of co-worker wage in old and new employer. Third, each job changer is assigned to one of the 16 possibles job transitions (from of the four quartiles in co-worker wage of the old employer to the new employer). Finally, we calculate the average observed wage of job-changers for each specific job transition before and after the job change. Figure B1 shows the results of this exercise. The first reassuring feature of Figure B1 is the approximate symmetry in the patter of wage for workers that move between quartile 1 and 4 (similar symmetry is observed for other mover category - in particular for those moving from 4 th to 2 nd and from 1 st to $3 r d) .{ }^{55}$ This suggests that the choice to work for a specific firm does not depend on the expected surplus component of the worker-firm match (allowing us to not explicitly include worker-firm match fixed effects in the AKM decomposition). In other words, we do not observe sorting of workers based on the match component. This qualitative evidence supports the validity of the the simple model with additive worker and firm effect at the base of the AKM decomposition.

To obtain unbiased estimations of worker and firm effects from AKM decomposition, we need to check that job moves do not depend on drift in worker's expected wage (included in the residual term of the additive model in AKM). The absence of any substantial trend in wage before the move towards a better firms, suggests the absence of a learning process (drift) that may bias the estimations. Finally, unbiased estimation of worker and firm effects also requires that the transitory error component of the additive model is not associated with systematic movements across firms of different quartiles. The fact that pre-move wage dynamics are almost flat, and the symmetry in the wage pattern across firms of different quartiles reduce any concern of job mobility related to transitory wage fluctuations.

\footnotetext{
${ }^{55}$ The patter shown in figure B1 emerges after adjusting wage dynamics for time trend.
} 
An additional validity check for the AKM decomposition (and the underlying additive wage model) is testing the improvement in the fit of the data after explicitly including match fixed effects in the estimation of equation (18) as done in Card et al. (2013) and Dauth et al. (2018). Consistently with the additive nature of equation (18), we find that the inclusion of job-specific fixed effects only marginally improves the R-square of the AKM estimation: from 0.947 to 0.950 (Root MSE from 0.114 to 0.111 ). Finally, in table B1 we report some descriptive statistics of the parameters obtained from the AKM decomposition computed over the period 1995-2005. We have approximately 2 million worker-firm observations, and the average $(\ln )$ wage is equal to 9.8 with a standard deviation equal to 0.46 . In line with results in table III in Card et al. (2013), we also obtain a standard deviation of worker effects larger than firm effects.

\section{Figure B1 - Mean Wages of Job Changers Classified by Quartile of Mean Wage of Cowork- ers at Origin and Destination Firm.}

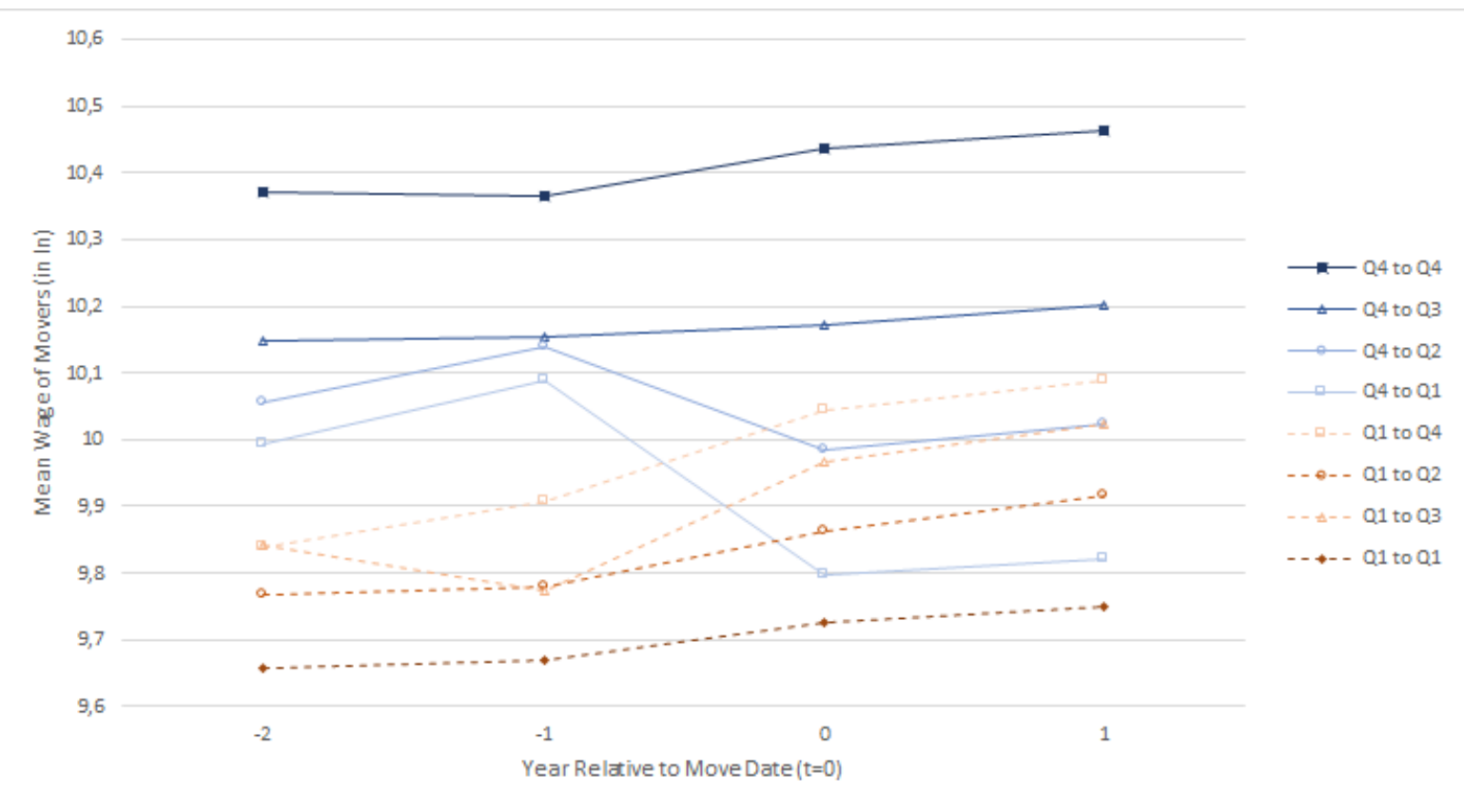

Source: Authors calculations on DADS and Ficus/Fare data. Note: The figure shows wage levels of job movers in the period 1995-2005 at old firm two years prior to the move ( $t=-2$ and $t=-1)$; and the wage levels at the new firm in the year of the move $(t=0)$ and the year after $(t=1)$. These have been obtained by average wage of movers classified by the quartile of co-worker wages in the old and new firm. 
Table B1 - Estimation results for AKM model.

\begin{tabular}{lc}
\hline \hline & Period 1995-2005 \\
\hline Worker and firm parameter & 408666 \\
Number worker effects & 95942 \\
Number firm fixed effects & \\
\hline Summary of parameter estimates & 0.000 \\
Mean worker effects (across worker-year obs) & 0.000 \\
Mean firm effects (across worker-year obs) & -0.038 \\
Median worker effects (across worker-year obs) & -0.002 \\
Median firm effects (across worker-year obs) & 0.990 \\
Std. Dev. worker effects (across worker-year obs) & 0.246 \\
Std. Dev. firm effects (across worker-year obs) & -0.182 \\
Correlation(worker FE, firm FE) & 0.954 \\
R-squared & \\
\hline Other statistics & 9.863 \\
Average log wage & 0.465 \\
Std dev log wage & 1904423 \\
Sample size & \\
\hline
\end{tabular}




\section{Rotemberg weights and validity tests}

The identification of the shift-share IV adopted here bases on the exogeneity of the initial shares of migrants used to allocate origin-specific and time variant migration inflows (Goldsmith-Pinkham et al. 2019). This section aims at strengthening the credibility of our empirical design by applying some specification tests on the initial (origin-specific) migrants shares that have the highest impact on our baseline 2SLS results. Namely, we calculate the Rotemberg weights for each origin-specific share of immigrants in 1982 and apply the specification validity tests prescribed by Goldsmith-Pinkham et al. (2019) for the top-5 origins in terms of Rotemberg weights. Such weights depend on the covariance between the fitted value of each origin-specific migration share on the endogenous variable and the endogenous variable itself, and intuitively tell how sensitive is the overidentified estimate of the coefficient of interest ( $/ \mathrm{mmmi}$ sh in our setting) to the mispecification in any of the origin-specific migrant share. In practice, such weights reveal which specific migrants communities (in 1982) have more importance in the overall 2SLS estimate. So testing the specification validity for the sub-sample of origin-specific shares that affect the most the overall 2SLS estimation will reassure on the general validity of our estimations.

In line with the LFS data in 1982 used to build the origin-specific shares of migrants in 1982, we have 22 origins $0 .{ }^{56}$ Panel 2 of table $\mathrm{C} 1$ shows that the top-origin in terms of weights is the "Other Countries n.e.c." (covering mainly South American and other Asian countries) which receives itself almost half of the weight. The top-5 countries (in order of Rotemberg weights: Other Countries n.e.c., Other African countries, Portugal, Ex-Yugoslavian countries, Algeria) account for almost the $80 \%$ of the overall weight. The large weight for the macro origin "Other Countries n.e.c." is not surprising as it includes big migrants communities in France (such as the Chinese, the Indian and the South American ones) and mimic the big Rotemberg weigth associated to Mexico obtained by Goldsmith-Pinkham et al. (2019) for the US immigration example. Also, in panel 1 of table $\mathrm{C} 1$ we show that the correlation

\footnotetext{
${ }^{56}$ The 22 origins in LFS data are: Algeria, Tunisia, Morocco, Other African countries, Vietnam-Laos-Cambodia, Italy, Germany, Belgium, Netherlands, Luxembourg, Ireland, Denmark, UK, Greece, Spain, Portugal, Switzerland, Austria, Poland, Ex-Yugoslavia, Turkey, and Other Countries n.e.c.
} 
between weights and the migrants inflows is very high (0.96), suggesting that weights are considerably explained by shocks (another feature in common with the enclave IV applied to the US case in Goldsmith-Pinkham et al. 2019).

With the list of top-5 migrants origins in terms of Rotemberg weights we can test the plausibility of our identifying assumption. First, in table $C 2$ we show the correlation between initial migration shares across districts for each of the top- 5 origins and the average district's wage in 1982 (we only have LFS data for the year 1982, and so very limited choices in terms of variables approximating the economic performance of districts in 1982). The absence of correlation suggests that the initial settlement of immigrants (by origin) across French districts does not reflect the level of the economic performance of the local labor market. ${ }^{57}$ Second, we replicate the pre-trend exercise as presented in Goldsmith-Pinkham et al. (2019) for each of the top-5 origins highlighted here. Namely, we regress respectively our four measures of strength of PAM in the starting year (1995) on the origin-specific share of immigrants in 1982 (including the same set of controls $X_{d}$ included in equation C2 for the year in 1995). Results reported in table C3 show that the variation in the initial originspecific share of immigrants did not predict statistically or economically larger strength of PAM across districts (no matter the measure of PAM adopted). This, combined with our baseline results, suggests that there has been a shock in the share of immigrants over the period 1995-2005 that improved the strength of PAM.

Finally, in figure C1 we report the correlation between the point estimates for each of the origin-specific instrument $(\hat{\beta})$, and the first-stage F-statistics. The absence of a specific pattern suggests the overidentification tests (for each of the IV) fails to reject the null. This is a further element in favor of the validity of the overall IV used in our baseline estimations.

\footnotetext{
${ }^{57}$ For a proper correlation test, as prescribed by Goldsmith-Pinkham et al. (2019) we should have correlated initial migrants share with the PAM measures in 1982. These are unfortunately not available for the year 1982 so we used average wage as a proxy for the economic performance of the local labor market.
} 
Table C1 - Summary of the Rotemberg weights

\begin{tabular}{lccccc}
\hline \hline Panel I: Correlations & & & & & \\
& $\hat{\alpha}_{k}$ & $g_{k}$ & $\hat{\beta}_{k}$ & $\hat{F}_{k}$ & $\operatorname{Var}\left(z_{k}\right)$ \\
\cline { 2 - 5 }$\hat{\alpha}_{k}$ & 1 & & & & \\
$g_{k}$ & 0.958 & 1 & & & \\
$\hat{\beta}_{k}$ & 0.087 & 0.056 & 1 & & \\
$\hat{F}_{k}$ & 0.217 & 0.222 & 0.050 & 1 & \\
$\operatorname{Var}\left(z_{k}\right)$ & 0.052 & -0.114 & 0.008 & -0.311 & 1 \\
\hline Panel II: Top-5 Rotemberg weight origins & & & & & \\
\cline { 2 - 5 } & & & & & \\
Other Countries n.e.c. & $\hat{\alpha}_{k}$ & $g_{k}$ & $\hat{\beta}_{k}$ & & \\
Other African countries & 0.585 & $2.17 \mathrm{e}+06$ & 0.674 & & \\
Portugal & 0.075 & $7.35 \mathrm{e}+05$ & 1.425 & & \\
Ex-Yugoslavia & 0.047 & $5.28 \mathrm{e}+05$ & 0.603 & & \\
Algeria & 0.045 & $1.87 \mathrm{e}+05$ & -0.111 & & \\
\hline
\end{tabular}

\section{Panel III: Variation across years in $\hat{\alpha}_{k}$}

1995

2000

2005

\begin{tabular}{cc} 
Sum & Mean \\
\hline 0.025 & 0.001 \\
0.083 & 0.004 \\
0.184 & 0.008
\end{tabular}

Notes: This table reports statistics about the Rotemberg weights obtained following the procedure described in Goldsmith-Pinkham et al. (2019) and adapted to our specific empirical framework. Panel I report the correlations between weights $\left(\hat{\alpha}_{k}\right)$, the French inflow of migrants from a given origin $k,\left(g_{k}\right)$, the just-identified point estimate $\hat{\beta}_{k}$, the first stage F-stat $\left(\hat{F}_{k}\right)$, and the variation in the origin country shares across districts $\left(\operatorname{Var}\left(z_{k}\right)\right)$. Panel II report the top-5 origin countries in terms of Rotemberg weights. Panel III reports the variation in the weights across years.

Table C2 - Relationship between industry shares and labor market characteristic in $\mathbf{1 9 8 2}$

\begin{tabular}{lccccc}
\hline \hline Dep Var: & \multicolumn{5}{c}{ Share of immigrants in 1982 originating from } \\
\cline { 2 - 6 } & $\begin{array}{c}\text { Other } \\
\text { countries } \\
\text { n.e.c. }\end{array}$ & $\begin{array}{c}\text { Other } \\
\text { African } \\
\text { countries }\end{array}$ & Portugal & Ex-Yugoslavia & Algeria \\
& -0.003 & -0.000 & $0.005^{* *}$ & 0.002 & 0.004 \\
\hline Avg wage in 1982 & $(0.009)$ & $(0.004)$ & $(0.002)$ & $(0.006)$ & $(0.004)$ \\
& 92 & 92 & 92 & 92 & 92 \\
Observations & 0.391 & 0.620 & 0.765 & 0.348 & 0.453 \\
R-squared &
\end{tabular}

Notes: Each column shows the results of a regression of a given (origin-specific) share of immigrants in 1982 on the average wage across districts in 1982 (conditioned on region fixed effects). Robust standard errors in parenthesis. $* * * p<0,01 ; * * p<0,05 ; * p<0,1$. 
Table C3 - Pre-trend for high Rotemberg weight origins

\begin{tabular}{lccccc}
\hline \hline Dep Var: & \multicolumn{5}{c}{ Share of immigrants in 1982 originating from } \\
\cline { 2 - 6 } & $\begin{array}{c}\text { Other } \\
\text { countries } \\
\text { n.e.c. }\end{array}$ & $\begin{array}{c}\text { Other } \\
\text { African } \\
\text { countries }\end{array}$ & Portugal & Ex-Yugoslavia & Algeria \\
& 0.104 & 0.387 & -0.958 & -0.108 & -0.111 \\
Rank Correlation (lifetime as worker type) & $(0.166)$ & $(0.420)$ & $(0.852)$ & $(0.245)$ & $(0.397)$ \\
& 0.078 & 0.448 & -0.794 & -0.120 & 0.152 \\
Rank Correlation (AKM f.e. as worker type) & $(0.172)$ & $(0.408)$ & $(1.065)$ & $(0.221)$ & $(0.477)$ \\
& 0.152 & $0.613^{*}$ & -1.022 & 0.048 & -0.013 \\
Strength of PAM (lifetime as worker type) & $(0.166)$ & $(0.329)$ & $(0.955)$ & $(0.249)$ & $(0.298)$ \\
Strength of PAM (AKM f.e. as worker type) & 0.185 & 0.394 & -1.035 & 0.011 & 0.061 \\
& $(0.141)$ & $(0.341)$ & $(0.996)$ & $(0.230)$ & $(0.414)$ \\
\hline \hline
\end{tabular}

Notes: Each entry of the table reports the results of a regression specification having a proxy for the strength of PAM in 1995 as dependent variable and the 1982 share of immigrant for a given origin country. The same set of control as in eq. 13 , and region fixed effects are included in such specifications. Robust standard errors in parenthesis. *** $p<0,01 ; * * p<0,05 ; * p<0,1$.

Figure C1 - Heterogeneity of $\hat{\beta}$ on origin-specific IVs.

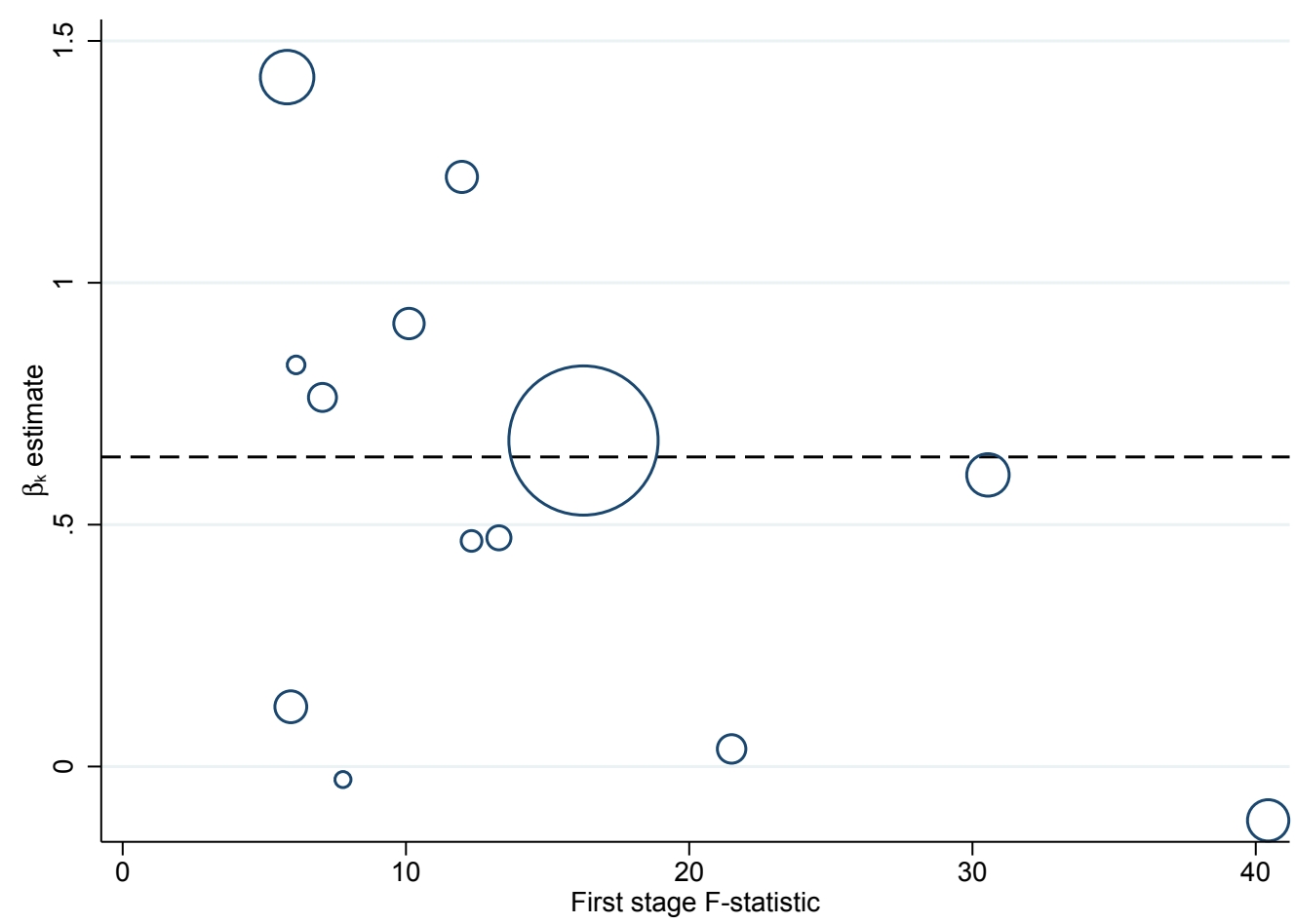

Note: This figure shows the relationship between each origin specific IV's point estimate $\hat{\beta}$ and the first stage F-stat. Each point is a separate origin-specific IV estimate, and the size of the points reflects the magnitude of the Rotemberg weight. We report only instruments with high enough power, i.e. F-stat above 5. 